\title{
LAS RELACIONES INTERGUBERNAMENTALES EN EL NUEVO ESTATUTO DE AUTONOMÍA DE ANDALUCIA
}

\author{
POR \\ JOSÉ JOAQUÍN FERNÁNDEZ ALLES \\ Doctor en Derecho \\ Profesor Titular de Derecho Constitucional \\ Universidad de Cádiz
}

\section{LAS «RELACIONES INSTITUCIONALES» EN EL NUEVO ESTATUTO ANDALUZ}

Las "relaciones institucionales de la Comunidad Autónoma» ${ }^{1}$, según la expresión que finalmente decidió adoptar el legislador como rú-

${ }^{1}$ Cfr. Propuesta de Reforma de Estatuto de Autonomía. 127/000004 Propuesta de reforma del Estatuto de Autonomía para Andalucía. Presentada por el Parlamento de Andalucía. BOCG Congreso de los Diputados VIII Legislatura. Serie B: Proposiciones de Ley 30 de Octubre de 2006. Núm. 246-7, pp. 249-298; y BOCG Senado. VIII legislatura Serie III B: Proposiciones de Ley del Congreso de los Diputados. 29 de noviembre de 2006. Núm. 18 (c) (Cong. Diputados, Serie B, núm. 246 Núm. exp. 127/000004). Reforma de Estatutos de Autonomía. 605/000003 Propuesta de reforma del Estatuto de Autonomía para Andalucía. Informe de la Ponencia, pp. 88-146. La redacción originaria de la Propuesta de Estatuto contenía la siguiente rúbrica, técnicamente inadecuada en términos de constitucionalidad y legalidad: Título IX. $R e-$ laciones Externas de la Comunidad Autónoma; y Propuesta de reforma del Estatuto de Autonomía para Andalucía. Informe elevado por la Ponencia para la reforma del 
brica del Título IX del Estatuto de Autonomía ${ }^{2}$, constituye, junto a la Declaración de los Derechos (Título I) y a la propia filosofía constitucional de las reformas territoriales de la VIII Legislatura, la gran novedad en el contenido de la norma institucional básica andaluza tramitada en las Cortes Generales ${ }^{3}$. Si formalmente los respectivos títulos reguladores de las competencias, la hacienda o la reforma de la "norma institucional básica de la Comunidad Autónoma» - incluso también algunos artículos relativos a los derechos y las libertades- ya se incluían en el Estatuto de 1981, hasta ahora no había un Título completo sobre las relaciones institucionales, sólo la regulación fragmentaria de los artículos 72 y 73 del Título V de la LO 6/1981, de 30 de noviembre (Relaciones con la Administración del Estado y con otras Comunidades Autónomas), limitada a los convenios, la solicitud de tratados internacionales y a la repetida representación del Presidente de la Junta de Andalucía. Preceptos que ignoraban la necesaria normación que sobre esta materia de las relaciones intergubernamentales - ausente del texto constitucional- hace ya casi treinta años advirtieron algunos profesores norteamericanos $y$ alemanes como correlato ineludible de la organización territorial descentralizada que permitía la Constitución de $1978^{4}$.

Estatuto de Autonomía para Andalucía a la Comisión de Desarrollo Estatutario 20.894. Núm. 372 Séptima Legislatura Andalucía, 7 de febrero de 2006. P. núm. 20.894 Andalucía, 7 de febrero de 2006, BOPA, núm. 372.

2 La proposición originaria del texto originario dedicaba a todo el Título la rúbrica de "relaciones externas", sustituida, con evidente mejora técnica, en la fase de enmiendas ante el Parlamento de Andalucía por "Relaciones Institucionales". La expresión «Relaciones externas», de escasa tradición en el lenguaje jurídico, parecía hacer referencia a las relaciones con el exterior que, en el texto final se contemplan en el Capítulo IV: "Relaciones con el exterior».Véanse los artículos 193-200 de la LO 6/2006, en su Capítulo III. "Acción exterior de la Generalitat. (...)». Una enmienda al Título IX, presentada en el Congreso de los Diputados por el Grupo Parlamentario Popular, solicitaba la siguiente denominación: «De las relaciones institucionales de Andalucía». Cfr. Boletín Oficial de las Cortes Generales Congreso de los Diputados VIII Legislatura. Serie B: Proposiciones de Ley 13 de septiembre de 2006. Núm. 246-5. Propuesta de Reforma de Estatuto de Autonomía. Enmiendas e índice e enmiendas al articulado.127/000004, p. 155.

3 Cfr. Propuesta de reforma del Estatuto de Autonomía para Andalucía. Comisión Constitucional. BOCG. Congreso de los Diputados Núm. B-246-1 de 12/05/2006 Pág.: 1; BOCG. Congreso de los Diputados Núm. B-246-2 de 26/05/2006 p. 49; BOCG. Congreso de los Diputados Núm. B-246-3 de 02/06/2006, p.: 51; BOCG. Congreso de los Diputados Núm. B-246-4 de 21/06/2006, p. 53; Diarios de Sesiones. Congreso de los Diputados Núm. 179 de 23/05/2006, p. 8928; y Propuesta de Reforma de Estatuto de Autonomía, cit., pp. 293 y ss.

${ }^{4}$ Cfr. D. J. ElAZAR y de D. S. WRIGHT, Understanding Intergovernmental Relations. Harcourt Brace y Co. 1988; H. P. SCHNEIDER. y K. SEIDEL, "Administración del Es- 
La vocación relacional de los Estados descentralizados - muy desatendida por los Estatutos de Autonomía y, en general, por el bloque de la constitucionalidad - deriva de una rica y valiosa experiencia comparada, que en España sólo ha encontrado una plasmación legislativa relevante en el año 2006, justo un cuarto de siglo después de la aprobación de los primeros Estatutos de Autonomía ${ }^{5}$, aunque todavía sin un sistema de relaciones intergubernamentales que vincule de modo completo a los distintos niveles de poder político territorial, como ocurre desde hace décadas de los Estatutos y Constituciones de los entes territoriales de Europa y América: Italia, Estados Unidos de América, Alemania o México ${ }^{6}$.

En efecto, si analizamos los Estatutos de Baleares, Canarias, Cantabria, Castilla-León, Castilla-La Mancha, Galicia, Extremadura, Madrid, Murcia, País Vasco, Asturias o incluso la Ley Orgánica que ha regido la Comunidad Autónoma de Cataluña hasta el nuevo Estatuto de la LO $6 / 2006$, comprobamos el escaso interés normativo que en nuestro Estado de las Autonomías han suscitado las relaciones institucionales y, en particular, las intergubernamentales. $Y$ aunque ciertamente los Estatutos de La Rioja (Convenios con otras CCAA), Aragón (Relaciones CA con los

tado federal", AA.VV. La Administración del Estado en las Comunidades Autónomas, Barcelona, Institut dEstudis Autonòmics, 1997; K. STERN, Derecho del Estado de la República Federal Alemana, Madrid, CEC, 1987; E. KATZ, "El federalismo norteamericano: pasado, presente y futuro", Temas de la Democracia, Publicación Electrónica de USIS, Vol. 2, No. 2, mayo de 1997. H. SCHNEIDER, «El Estado federal cooperativo", REP, n. ${ }^{\circ} 12$ de 1979, pp. 41-61.

${ }^{5}$ Durante el debate sobre el estado de la Comunidad Autónoma de Andalucía del año 2003 el Presidente de la Junta de Andalucía anunció la presentación de un documento con propuestas para la reforma del Estatuto de Autonomía: Bases para la Reforma del Estatuto de Autonomía para Andalucía. BOPA núm. 33, 6 de julio de 2004, BOPA núm. 372 Andalucía, 7 de febrero de 2006, p. núm. 20.895, BOPA núm. 197, 13 de mayo de 2005, BOPA núm. 372 Andalucía, 7 de febrero de 2006, p. núm. 20.989.

6 Valga como ejemplo el Estatuto de Cerdeña (Sardegna, Statuto speciale) (L.cost. 26 febbraio 1948, n. 3, modif. con I.cost. 23 settembre 1993, n. 22, e con I.cost. 31 gennaio 2001, n. 2). Título VI. Rapporti fra lo Stato e la Regione. Véase también R. Agranoff, y R. BAÑón, El Estado de las Autonomías. ¿Hacia un nuevo Federalismo? Instituto Vasco de Administración Pública: Vitoria-Gasteiz, 1998; R. GomÀ y J. SUBIRATS, coords., Políticas públicas en España. Contenidos, redes de actores y niveles de gobierno. Barcelona, Ariel, 1998; López Aranguren, E., Relaciones Intergubernamentales en los estados Autonómico y Federal. Estudio sobre los Estados Unidos, el Estado Español y el País Vasco. IVAP: OÑATE, 2002; y MoRATA, F., "Relaciones intergubernamentales y políticas públicas", Documentación Administrativa 224225, 1992, pp. 153-166. 
entes locales), Navarra (relaciones con el Estado y convenios con las CCAA), Valencia (Convenios y más completa en la LO 1/2006 ${ }^{7}$ ) o Andalucía en 1981 (arts. 72 y 73) han regulado algunas relaciones con el Estado y con los Entes Locales, así como los convenios horizontales con otras Comunidades Autónomas, se trata de una regulación dispersa y fragmentaria que no adopta un sistema de relación entre niveles entre gobierno. Incluso el Estatuto de Cataluña de la LO 6/2006 se debe considerar una oportunidad perdida que, además de contravenir el principio de eficacia e incurrir en el denominado "mal federalismo cooperativo", en esta materia suscita dudas de constitucionalidad que han sido alegadas en los recursos presentados ante el Tribunal Constitucional por el Partido Popular, el Defensor del Pueblo y diversas Comunidades Autónomas: Aragón, Valencia, Baleares, La Rioja y Murciå

En el caso andaluz, el Estatuto de Autonomía de 1981 incluye en su Título V, sobre Relaciones con la Administración del Estado y con otras Comunidades Autónomas, dos preceptos: en el artículo 73 EAA, que reproduce la previsión constitucional del artículo $152 \mathrm{CE}$ : «corresponde al Presidente la representación de la Comunidad Autónoma de Andalucía en sus relaciones con el Estado y con las demás Comunidades Autónomas ${ }^{9}, y$, el artículo precedente, que dispone de forma concisa sobre

7 Véase el Título V de la LO 1/2006, de 10 de abril, de Reforma de la Ley Orgánica 5/1982, de 1 de julio, de Estatuto de Autonomía de la Comunidad Valenciana, sobre Relaciones con el Estado y otras Comunidades Autónomas, dispone en su artículo 59.1. La Generalitat, a través del Consell, podrá celebrar convenios de colaboración para la gestión y prestación de servicios correspondientes a materias de su exclusiva competencia, tanto con el Estado como con otras comunidades autónomas.

${ }^{8}$ El Recurso de Inconstitucionalidad del Partido Popular afirma sobre el Título V del Estatuto de Autonomía de Cataluña "De las Relaciones Institucionales de la Generalitat». El principio de bilateralidad es uno de los hilos conductores del nuevo Estatuto de Autonomía de Cataluña. Corolario de la "posición singular» de la Generalitat de Cataluña que enuncia el Preámbulo. Este principio aparece recogido en el artículo 3 del Estatuto (...). Y se concreta a lo largo de todo el texto estatutario, pero especialmente en el Título IV, como acabamos de analizar, y en el Título V. Cfr. Recurso de Inconstitucionalidad 1/2006, de 19 de septiembre de 2006, contra determinados preceptos del nuevo Estatuto de Autonomía de Cataluña, aprobado por Ley Orgánica 6/2006, de 19 de julio y publicado en el Boletín Oficial del Estado de 20 de julio de 2006, pp. 312 y 313; y La LO 6/2006, de 19 de julio, regula en el Título V, De las relaciones institucionales de la Generalitat (artículos 174-200). BOE 172, de 20 de julio de 2006, pp. 27.301- 27.304.

9 Esta materia se incluye en la LO 6/2006, reguladora del Estatuto de Autonomía de Cataluña, en el Capítulo I del Título V, sobre Relaciones de la Generalitat con el Estado y con otras Comunidades Autónomas, donde se establece una disposiciones generales en el artículo 174. 
los convenios horizontales: "en los supuestos, condiciones y requisitos que determine el Parlamento, la Comunidad Autónoma puede celebrar Convenios con otras Comunidades para la gestión y prestación conjunta de servicios propios de las mismas» (párr. 1). Según el párrafo 72. 2, "la Comunidad Autónoma podrá celebrar Convenios con otras Comunidades para la gestión y prestación de servicios de actos de carácter cultural, especialmente dirigidos a los emigrantes de origen andaluz residentes en dichas Comunidades". El deber de lealtad constitucional se concreta en el párrafo 3, según el cual, el Parlamento comunicará a las Cortes Generales, a través del Presidente, la celebración, en su caso, de los Convenios que entrarán en vigor a los treinta días de tal comunicación. Si las Cortes Generales o alguna de las Cámaras formularan objeciones en dicho plazo, a partir de la recepción de la comunicación, el Parlamento habrá de solicitar autorización de las Cortes Generales, que será obligatoria para concertar acuerdos de cooperación con otras Comunidades Autónomas. Al Parlamento compete determinar el alcance, la forma y el contenido de dichos acuerdos. Finalmente, en el mismo artículo donde se regulan los convenios de eficacia interna, el párrafo 5 del artículo 72 establece que "la Comunidad Autónoma podrá solicitar del Gobierno que celebre y presente, en su caso, a las Cortes Generales, para su autorización, los tratados o convenios que permitan el establecimiento de relaciones culturales con los estados con los que mantengan particulares vínculos culturales o históricos".

En consecuencia, como sucede en la mayoría de los Estatutos de Autonomía, el primer texto estatutario andaluz omite los contenidos esenciales de las relaciones intergubernamentales, ignora las más conocidas regulaciones previstas en Derecho comparado ${ }^{10}$ e incluso olvida aspectos tales como las técnicas de relación que la Constitución prevé (las delegaciones de funciones, los instrumentos de control ${ }^{11} \ldots$ ),

10 Sobre las relaciones de control, valga como ejemplo, el Estatuto especial de Friuli-Venezia Giulia, Título VII. Rapporti tra Stato e Regione. Art. 61. È istituito, nella Regione, un Commissario del Governo, residente nel capoluogo della Regione stessa. Il Commissario è un funzionario dello Stato avente qualifica non inferiore a direttore generale o equiparata, nominato con decreto del Presidente della Repubblica, su proposta del Presidente del Consiglio dei Ministri, di concerto con il Ministro per l'interno, sentito il Consiglio dei Ministri.

11 Sobre las relaciones Estado-región, art. 47. 1. II Presidente della Regione dirige le funzioni amministrative delegate dallo Stato alla Regione, conformandosi alle istruzioni del Governo.2. Egli interviene alle sedute del Consiglio dei ministri, quando si trattano questioni che riguardano particolarmente la Regione. Art. 48. 1. Un 
el fundamento de estas relaciones (los principios de eficacia, subsidiariedad ${ }^{12} \ldots$ ) o las relaciones con el Delegado del Gobierno, de relevante función constitucional (art. $154 \mathrm{CE}$ ) y amplia regulación en Derecho Comparado. Tampoco incorpora la terminología y conceptos de las "relaciones intergubernamentales", presentes en el ordenamiento jurídico de Italia, Estados Unidos de América, Canadá o Alemania (The Three Levels System of Intergovernmental Relations) ${ }^{13}$.

Por último, debe advertirse que, por razones metodológicas y terminológicas, la expresión "Relaciones institucionales» elegida por el legislador no parece técnicamente correcta cuando, como ocurre en el nuevo texto estatutario andaluz, en ella se incardina la categoría de las "relaciones normativas", que no son "institucionales", o cuando se olvida que como, en la mayoría de los preceptos del Título IX, esas re-

Rappresentante del Governo sovraintende alle funzioni amministrative dello Stato non delegate e le coordina con quelle esercitate dalla Regione. Art. 49.1. II Governo della Repubblica può delegare alla Regione le funzioni di tutela dell'ordine pubblico. Queste saranno esercitate, nell'ambito delle direttive fissate dal Governo, dal Presidente della Regione che, a tale scopo, potrà richiedere l'impiego delle forze armate. Art. 50. 1. II Consiglio regionale può essere sciolto quando compia atti contrari alla Costituzione o al presente Statuto o gravi violazioni di legge o quando, nonostante la segnalazione fatta dal Governo della Repubblica, non proceda alla sostituzione deIla Giunta regionale o del Presidente che abbiano compiuto analoghi atti o violazioni. Cfr. SARDEGNA, Statuto speciale. (L.cost. 26 febbraio 1948, n. 3, modif. con I.cost. 31 gennaio 2001, n. 2). Cfr. R. AgRANOFF, "Las relaciones y la gestión intergubernamental", R. Bañón y E. Carrillo, La nueva Administración Pública. Madrid. Alianza, 1997 , pp. 125 y ss.

${ }_{12}$ Sólo las encontramos en las relaciones con la Unión Europea, en el artículo 237 del nuevo texto andaluz y en el artículo 188 de la LO 6/2006. Participación en el control de los principios de subsidiariedad y de proporcionalidad, el Parlamento participará en los procedimientos de control de los principios de subsidiariedad y proporcionalidad que establezca el derecho de la Unión Europea en relación con las propuestas legislativas europeas cuando dichas propuestas afecten a competencias de la Generalitat. Con carácter general en la experiencia comparada, Constitución Política del Estado Libre y Soberano de Baja California. Publicada en el Periódico Oficial No. 23, de Fecha 16 de Agosto de 1953, Tomo LXVI. Artículo 11.- (...) Las relaciones entre el Municipio y el Gobierno del Estado se conducirán por los principios de subsidiariedad y equidad, en los términos de esta Constitución, con el propósito de lograr el desarrollo social y humano tendientes a mejorar la calidad de vida de los habitantes del Estado.

${ }_{13}$ Constitution of the State of Georgia. Ratified General Election, November 2, 1982; Governor's Proclamation, March 1,1983.Effective, July 1,1983. Article IX: Counties and Municipal Corporations. Section III: Intergovernmental Relations. Section IV: Taxation Power of County and Municipal Governments. Section III. Intergovernmental Relations. Paragraph I. Intergovernmental contracts. 
laciones son estrictamente "relaciones intergubernamentales" toda vez que sólo vinculan a niveles de "gobierno". Cuando la Comunidad Autónoma se relaciona con el Estado, con la Unión Europea o con los Entes locales, estamos fundamentalmente ante relaciones de carácter intergubernamental en el sentido acogido en la Ley 50/1997, de 27-11, del Gobierno: relaciones intergubernamentales que no involucran a todos los poderes horizontales del Estado sino sólo a los Gobiernos ${ }^{14}$. $Y$ cuando se relacionan estos gobiernos tampoco estamos ante relaciones institucionales, aunque tampoco meramente interadministrativas - como se las califica mayoritariamente en el ordenamiento jurídico español (incluso por el legislador, en el Título V, Capítulo II, Relaciones interadministrativas, arts. 55 a 62, de la Ley 7/1985, de 2 de abril)—, sino relaciones de carácter intergubernamental, ya que vinculan a dos o más gobiernos, quienes al relacionarse ejercitan su potestad de dirección política (indirizzo político, Staatsleitung). Esta confusión debe ser advertida porque el nuevo Estatuto de Autonomía de Andalucía no sólo mezcla, como veremos en las próximas páginas, las relaciones normativas y las relaciones orgánicas, sino que, además, tampoco parece atender sistemáticamente a los distintos niveles o dimensiones de las relaciones institucionales.

Aunque como avance respecto al Estatuto anterior el Título IX regula los elementos principales de estas relaciones (convenios, gestión de fondos europeos, toma de decisiones, comisiones...), llama la atención que la prolijidad estatutaria en otras materias no se extienda a los niveles de "relación intergubernamental» ignorados en el nuevo texto estatutario, entre los cuales sobresale el primero de ellos, el nivel relativo a las funciones de la Administración del Estado, tanto central como periférica, a través de las Comisiones Provinciales de Colaboración o, especialmente, del Delegado del Gobierno, quienes asumen una función de relación intergubernamental (control de las delegaciones, cooperación, coordinación) difícil de soslayar. Tampoco encontramos una adecuada regulación del segundo nivel de relación intergubernamental, sustanciado en el ámbito de relaciones entre el Gobierno de la Nación y el Consejo de Gobierno de Andalucía, como es el caso de los convenios de encomienda de gestión, las conferen-

14 El Parlamento cumple una función de control, información y publicidad respecto a actuaciones, convenios, iniciativas...Véase también como supuesto de relaciones interparlamentarias, el artículo 187. 4. de la LO 6/2006, "el Parlamento puede establecer relaciones con el Parlamento Europeo en ámbitos de interés común». Ibidem. 
cias sectoriales o las delegaciones del art. $150.2 \mathrm{CE}^{15}$. Tampoco el tercer nivel de relación intergubernamental, que cumple su cometido en el plano de las relaciones entre los gobiernos autonómicos y los gobiernos locales, ha derivado en la proclamación y concreción estatutaria del Pacto Local Andaluz ni en un sistema completo de relaciones con los entes locales y aún menos en un modelo de organización territorial vinculado a la ordenación territorial de Andalucía. Por último, sí se regulan las relaciones intergubernamentales con los órganos gubernamentales de la Unión Europea, en particular, en tareas de gestión y ejecución de programas y fondos comunitarios y las relaciones de cooperación transfronteriza.

\section{LAS RELACIONES CON EL EXTERIOR Y CON LA UNIÓN EUROPEA}

Los principios de relación entre la Comunidad Autónoma de Andalucía, con el Estado y la Unión Europea se establecen en el art. 10. 9., que fija como objetivo de la Comunidad Autónoma la convergencia con el resto del Estado y de la Unión Europea, promoviendo y manteniendo las necesarias relaciones de colaboración con el Estado y las demás Comunidades y Ciudades Autónomas, y propiciando la defensa de los intereses andaluces ante la Unión Europea. También el art. 10, sobre los objetivos básicos de la Comunidad Autónoma, fija en el apartado 6 . $^{\circ}$ como objetivo de la Comunidad, la creación de las condiciones indispensables para hacer posible el retorno de los andaluces en el exterior que lo deseen y para que contribuyan con su trabajo al bienestar colectivo del pueblo andaluz.

Estos objetivos se concretan al final del Estatuto de Autonomía, en el Capítulo III del Título IX, donde bajo la rúbrica de "Relaciones con las instituciones de la Unión Europea», se define el denominado "marco de relación": Ias relaciones de la Comunidad Autónoma de Andalucía con las instituciones de la Unión Europea se regirán por lo dispuesto en el

15 El Congreso de los Diputados suprimió una previsión en la Disposición Adicional 4. ${ }^{a}$, tras las enmiendas presentadas respectivamente por los Grupos Parlamentarios Socialista y Popular, justificadas por la inconstitucionalidad del precepto aprobado por el Parlamento de Andalucía: "Al amparo del artículo 150.2 de la Constitución, la Comunidad Autónoma de Andalucía asume, mediante transferencia o delegación, las facultades de ejecución (...) en las siguientes materias: a) Puertos y aeropuertos de interés general..." Cfr. Proposición de reforma, cit., BOJA 430 de 20 de mayo de 2006, p. 24.299. 
presente Estatuto y en el marco de lo que establezca la legislación del Estado (art. 230) ${ }^{16}$.

En general, el contenido del Capítulo III utiliza conceptos jurídicos que precisan de ulterior interpretación constitucional y responde a la confusión existente entre las relaciones orgánicas ${ }^{17}$ y las relaciones normativas, una clasificación tradicional en el Derecho que parece reemplazarse por la que distingue en la fase descendente de ejecución del derecho comunitario (art. 235) y la fase ascendente de formación de la voluntad del Estado (art. 231) y de la Unión Europea (art. 232), las cuales encuentran un primer nivel de regulación en la participación de la voluntad del Estado.

A) Relaciones orgánicas.- Los tres párrafos del artículo 231 regulan: a) El objeto de la participación, que viene determinado por la competencia o por el interés de la Comunidad Autónoma de Andalucía ${ }^{18}$ : "La Comunidad Autónoma participa en la formación de la posición del Es-

${ }^{16}$ Según la LO 1/2006, del Estatuto de Valencia, TíTULO VI. Relaciones con la Unión Europea. Artículo 61. 1. La Comunitat Valenciana tendrá una Delegación en Bruselas como órgano administrativo de representación, defensa y promoción de sus intereses multisectoriales ante las instituciones y órganos de la Unión Europea. 2. Asimismo, la Generalitat, a través del Organismo de Promoción de la Comunitat Valenciana, abrirá una red de oficinas de promoción de negocios en todos aquellos países y lugares donde crea que debe potenciarse la presencia de las empresas valencianas. 3. La Comunitat Valenciana, como región de la Unión Europea, sin perjuicio de la legislación del Estado: a) Participará en los mecanismos de control del principio de subsidiariedad previsto en el Derecho de la Unión Europea. b) Tiene derecho a participar (...). 4. La Generalitat, igualmente, podrá formar parte y participar en organizaciones e instituciones supranacionales de carácter regional. 5. Una Ley creará el Comité Valenciano para los Asuntos Europeos, órgano de carácter consultivo, encargado de asesorar y realizar estudios y propuestas para mejorar la participación en las cuestiones europeas y plantear acciones estratégicas de la Comunitat Valenciana.

17 Según la LO 1/2006, Título VII. Acción Exterior. Artículo 62. 1. La Generalitat, a través del Consell, podrá participar en la acción exterior del Estado cuanto ésta incida en el ámbito de sus competencias; también deberá ser oída en aquellos casos en que, sin ser de su competencia, puedan afectarle directa o indirectamente. En este sentido, de acuerdo con lo que determine la legislación española y europea, podrá: a) Instar al Gobierno de España a que celebre tratados o acuerdos, de carácter general o específicos, con otros Estados (...).

18 Según el Recurso del Partido Popular sobre el precepto similar del Estatuto Catalán -art. 184 LO 6/2006-, el precepto contempla de un manera tan amplia la participación que se prevé de la Generalidad que desborda el marco constitucional. Acude como criterio de conexión a la expresión "intereses de Cataluña», como algo diferente a las competencias que la misma tiene atribuídas. Una expresión tan amplia llevaría a que la Generalitat hubiese de participar prácticamente en todos los 
tado ante la Unión Europea en los asuntos relativos a las competencias o a los intereses de Andalucía, en los términos que establecen el presente Estatuto y la legislación sobre la materia» (art. 231.1) ${ }^{19}$; b) La forma de la participación, que podrá ser bilateral o multilateral, toda vez que según el art. 231.2 "La Comunidad Autónoma debe participar de forma bilateral en la formación de la posición del Estado en los asuntos que le afectan exclusivamente». En los demás, la participación se realizará en el marco de los procedimientos multilaterales que se establezcan; c) Un título de vinculación decisoria ha sido establecido en el párrafo 3, modificado en el Congreso de los Diputados: "La posición expresada por la Comunidad Autónoma es determinante en la formación de la posición estatal si afecta a sus competencias exclusivas y si de la propuesta o iniciativa europeas se pueden derivar consecuencias financieras o administrativas de especial relevancia para Andalucía». Una enmienda aprobada en el Congreso de los Diputados, ejemplo de abandono de la expresión "Gobierno de la Nación», cambió de orden y adelantó el siguiente párrafo anteriormente situado como inciso final del artículo: "Si esta posición no la acoge el Gobierno del Estado, éste debe motivarlo ante la Comisión Junta de Andalucía-Estado". «En los demás casos dicha posición deberá ser oída por el Estado». Pues bien, entre las dudas que suscita este precepto, se ha criticado doctrinalmente el concepto "acoger" - ¿aceptar?, ¿aprobar? ¿se trata de una propuesta preceptiva pero no vinculante?-y "determinante", término copiado del texto estatutario catalán cuyo artículo 186.3 de LO 6/2006 dispone sobre la «Participación en la formación de las posiciones del Estado": "La posición expresada por la Generalitat es determinante para la formación de la posición estatal si afecta a sus competencias exclusivas y si de la propuesta o iniciativa europeas se pueden derivar consecuencias financieras o administrativas de especial relevancia para Cataluña. En los demás casos, dicha posición debe ser oída por el Estado ${ }^{20}$. Aunque la misma justificación de la enmienda a

asuntos relacionados con la UE puesto que es realmente difícil encontrar alguna cuestión que de uno u otro modo no le afecte o interese. Recurso de inconstitucionalidad, cit., p. 311.

19 El artículo 199 de la Propuesta de Estatuto de Autonomía de Andalucía disponía: Participación en la voluntad del Estado: "La Comunidad Autónoma de Andalucía participa en la conformación de la voluntad del Estado ante las instituciones de la Unión Europea».

20 El recurso de inconstitucionalidad del Partido Popular contra la LO 6/2006, en relación con el artículo 186, apartados 1, 2, 3 y 4, tras afirmar que utilizan, respectivamente las expresiones: "participa en la formación»; "debe participar», "es determinante» e "informará a la Generalitat», dice que "el párrafo primero incurre en el mismo exceso que el precitado artículo 184 al hacerse extensivo a las competencias 
este párrafo, presentada por el Grupo Parlamentario Socialista en el Congreso de los Diputados, explica que "es necesario establecer qué alcance jurídico tiene la posición determinante de Andalucía", la redacción originaria ha permanecido igual en el texto aprobado por el Congreso de los Diputados, sin enmiendas posteriores en el Senado ${ }^{21}$.

Incurriendo en posible vulneración de los Tratados comunitarios, el artículo 232 contempla a sensu contrario la participación en las decisiones de la Unión Europea sin la presencia del Estado aunque «en los términos que legalmente se determinen" -expresión resultado de una enmienda aprobada en el Congreso de los Diputados-, según parece deducirse de una interpretación literal: "Andalucía participará en los procesos de decisión en las instituciones de la Unión Europea directamente o a través de la representación del Estado». Una redacción de dudosa constitucionalidad que ha sido matizada en la fase de enmiendas en el Congreso de los Diputados con el citado inciso final propuesto por el Grupo Parlamentario Socialista y finalmente aprobado en el texto estatutario definitivo: "en los términos que legalmente se determinen".

Según el artículo 234, esta "participación y representación en las instituciones y organismos de la Unión Europea" se articula de manera que la Junta de Andalucía participa en las delegaciones españolas ante las instituciones de la Unión Europea - «estará presente en las instituciones de la Unión Europea" rezaba la Proposición aprobada por el Parlamento de Andalucía- en defensa y promoción de sus intereses y para favorecer la necesaria integración de las políticas autonómicas con las estatales y las europeas. Se prevé en el mismo párrafo una cláusula relativa a una participación que debemos entender realizada a través de las delegaciones estatales «especialmente, participa ante el Consejo

o intereses de Cataluña", lo que le permitiría participar prácticamente en todo caso. La Generalitat no puede atribuirse una participación unilateral en la formación de las posiciones del Estado en la forma tan ambivalente como pretende este párrafo, en el que se parte de imponer esa participación aunque se remita a la "legislación sobre esta materia», sin explicitar que será, en todo caso, normativa estatal de general y multilateral aplicación (hoy por hoy, la regulación actualmente existente se condensa en la Resolución de 28 de febrero de 2005 de la Secretaría de Estado de Cooperación Territorial, que ordena la publicación de los Acuerdos de 9 de diciembre de 2004 de la Conferencia para Asuntos Relacionados con las Comunidades Europeas). Recurso, cit., pp. 313 y 314.

21 Cfr. Boletín Oficial de las Cortes Generales Congreso de los Diputados VIII Legislatura. Serie B: Proposiciones de Ley 13 de septiembre de 2006. Núm. 246-5. Propuesta de Reforma de Estatuto de Autonomía. Enmiendas e índice e enmiendas al articulado.127/000004, p. 175. 
de Ministros y en los procesos de consulta y preparación» - "en los órganos consultivos y preparatorios" según el texto aprobado en el Parlamento de Andalucía- del Consejo y la Comisión ${ }^{22}$, cuando se traten asuntos de la competencia legislativa de la Junta de Andalucía, en los términos que se establezcan en la legislación correspondiente ${ }^{23}$.

En cuanto a las órganos de representación en las sedes comunitarias, regulada por el Decreto 164/1995, de 27 de junio, regulador de la Delegación Permanente de la Junta de Andalucía en Bruselas, adscrita a la Consejería de la Presidencia, el artículo 236 del Estatuto establece sobre la Delegación Permanente de la Junta de Andalucía: «la Junta de Andalucía tendrá una Delegación Permanente en la Unión Europea como órgano administrativo de representación, defensa y promoción de sus intereses ante las instituciones y órganos de la misma, así como para recabar información y establecer mecanismos de relación y coordinación con los mismos» ${ }^{24}$.

En el párrafo 2 se contempla una participación pro futuro, actualmente no regulada ni practicada, que se condiciona a una expresión

22 El Artículo 203 de la Propuesta disponía bajo la rúbrica «Representación en las instituciones de la Unión Europea»: 1. La Comunidad Autónoma estará presente en las distintas instituciones de la Unión Europea en defensa y promoción de sus intereses y para favorecer la necesaria integración de las políticas autonómicas con las estatales y las comunitarias. Especialmente participará, en los términos que se establezcan ante el Consejo de Ministros y los órganos consultivos y preparatorios del Consejo y de la Comisión cuando se traten asuntos de la competencia legislativa de la Comunidad Autónoma. 2. La Junta de Andalucía, de acuerdo con el Estado, podrá designar miembros en la representación permanente de España en los organismos e instituciones de la Unión Europea.

${ }^{23}$ En la LO 6/2006, en el Capítulo II. Relaciones de la Generalitat con la Unión Europea, el artículo 184. Disposición General, dispone que la Generalitat participa, en los términos que establecen el presente Estatuto y la legislación del Estado, en los asuntos relacionados con la Unión Europea que afecten a las competencias o los intereses de Cataluña. Según el artículo 185. Participación en los tratados de la Unión Europea, 1. La Generalitat debe ser informada por el Gobierno del Estado de las iniciativas de revisión de los tratados de la Unión Europea y de los procesos de suscripción y ratificación subsiguientes (...).

${ }^{24}$ En la Propuesta de Estatuto se disponía: Artículo 206. Delegación permanente de la Junta de Andalucía: "La Junta de Andalucía podrá establecer en la sede de las instituciones europeas oficinas o agencias permanentes destinadas, en el marco de sus competencias, a recabar información sobre las actividades de tales instituciones así como a cumplir funciones de promoción, relación y coordinación con las mismas». Según la LO 6/2006, en su Artículo 192, sobre la delegación de la Generalitat ante la Unión Europea, la Generalitat establecerá una delegación para la mejor defensa de sus intereses ante las instituciones de la Unión Europea. 
técnicamente incorrecta — "previo acuerdo y por delegación»-, pero que quizás debería sustituirse por otra que haga referencia a la necesidad de contar con la habilitación normativa de una disposición comunitaria: "Cuando se refiera a competencias exclusivas de la Junta de Andalucía, la participación prevista en el apartado anterior permitirá, previo acuerdo y por delegación, ejercer la representación y la presidencia de estos órganos, atendiendo a lo previsto en la normativa que resulte de aplicación ${ }^{25}$.

En la fase descendente de ejecución del Derecho comunitario europeo, el artículo 185, sobre gestión de los fondos europeos, dispone que corresponde a la Comunidad Autónoma la gestión, planificación y ejecución de los fondos europeos destinados a Andalucía y, en general, de los que se canalicen a través de programas europeos asignados a la misma, en especial aquellos aprobados en aplicación de criterios de convergencia o derivados de la situación específica de Andalucía ${ }^{26}$. El párrafo 2 establece, a su vez, que los fondos que se reciban en estos conceptos podrán ser modulados con criterios sociales y territoriales por la Comunidad Autónoma de Andalucía, dentro del respeto a las normas europeas aplicables ${ }^{27}$.

Las relaciones con el Poder Judicial de la UE se reservan al artículo 238, Acciones ante el Tribunal de Justicia, cuyo párrafo 1 dispone que la Junta de Andalucía interviene en los procedimientos - "tendrá acceso" en el texto aprobado por el Parlamento de Andalucía- ante el Tribunal

25 El Congreso de los Diputados suprimió los párrafos 3 («La Junta de Andalucía, de acuerdo con el Estado, podrá designar miembros en la representación permanente de España en los organismos e instituciones de la Unión Europea») y 4 (Sobre los órganos consultivos, sólo se prevé en el párrafo 4 que "la Junta de Andalucía propondrá la designación de representantes en el Comité de las Regiones, de conformidad con las normas que lo regulan»). El artículo 204 de la Propuesta de Estatuto, bajo la rúbrica «Presencia de las regiones» disponía: "Los poderes públicos de Andalucía impulsarán la presencia de las regiones en la definición de las políticas de la Unión Europea». Ibidem.

26 Según la Propuesta de Estatuto, en su artículo 209. Gestión de fondos europeos: "Corresponde a la Comunidad Autónoma la gestión de los fondos provenientes de la Unión Europea y, en general, de los que se canalicen a través de programas europeos salvo que las competencias de ejecución en la materia objeto de la financiación correspondan al Estado".

27 El Congreso de los Diputados suprimió el párrafo 3, según el cual, la cuantía de los fondos estructurales de la Unión Europea que se asignen a Andalucía se determinará de acuerdo con los criterios empleados por aquélla en esta materia. Según la LO 6/2006, en su artículo 190, sobre gestión de fondos europeos, corresponde a la Generalitat la gestión de los fondos europeos en materias de su competencia en los términos previstos en los arts. 114 y 210. 
de Justicia de la Unión Europea en los términos que establezca la legislación del Estado - "legislación comunitaria» según el texto aprobado en Sevilla-. Según el párrafo 2 «En el marco de la legislación vigente en la materia, la Junta de Andalucía podrá instar al Estado y a las instituciones legitimadas el inicio de acciones ante el Tribunal de Justicia de la Unión Europea en defensa de los intereses de la Comunidad Autónoma» ${ }^{28}$.

B) Relaciones derivadas del principio de lealtad constitucional.- En cuanto a los deberes derivados del principio de lealtad constitucional en las relaciones Estado-Junta de Andalucía, el artículo 233 dispone que "el Estado informará a la Junta de Andalucía de las iniciativas, las propuestas y los proyectos normativos y las decisiones de tramitación en la Unión Europea, así como de los procedimientos que se sigan ante los órganos judiciales europeos en los que España sea parte, en lo que afecte al interés de Andalucía, conforme a lo establecido en la normativa estatal. La Junta de Andalucía podrá dirigir al Estado las observaciones y propuestas que estime convenientes» ${ }^{29}$.

Según el artículo 240, sobre Tratados y convenios, la Junta de Andalucía será preceptivamente informada por el Estado de los actos de celebración de aquellos tratados y convenios internacionales que afecten directa y singularmente a materias de su competencia. Tenor literal que reemplazó a la dudosamente constitucional: «intervendrá en el proceso de elaboración, modificación y denuncia de tratados y conve-

${ }^{28}$ En los términos de la Propuesta de Estatuto, disponía el artículo 208: Acciones ante el Tribunal de Justicia: 1. La Junta de Andalucía tiene acceso al Tribunal de Justicia de la Unión Europea en los términos que establezca la legislación comunitaria. 2. En los restantes supuestos el Consejo de Gobierno podrá instar al Estado y a las instituciones legitimadas el inicio de acciones ante el Tribunal de Justicia de la Unión Europea en defensa de los intereses de la Comunidad Autónoma. Según la LO 6/2006, en su Artículo 191. Acciones ante el Tribunal de Justicia, 1. La Generalitat tiene acceso al Tribunal de Justicia de la Unión Europea en los términos que establezca la normativa europea. 2. El Gobierno de la Generalitat puede instar al Gobierno del Estado a iniciar acciones ante el Tribunal de Justicia de la Unión Europea en defensa de los legítimos intereses y competencias de la Generalitat. La Generalitat colabora en la defensa jurídica. La negativa del Gobierno del Estado a ejercer las acciones solicitadas debe ser motivada y se comunicará inmediatamente a la Generalitat.

29 El artículo 202 de la Propuesta de Estatuto, bajo la rúbrica «Información del Gobierno central» disponía: El Gobierno central informará a la Comunidad Autónoma sobre las iniciativas y propuestas en tramitación en la Unión Europea, así como sobre los procedimientos judiciales en los que la Comunidad Autónoma sea parte. La Comunidad Autónoma podrá dirigir al Gobierno central las observaciones y propuestas que estime convenientes. 
nios internacionales que afecten a materias de su específico interés ${ }^{30}$. Asimismo, en virtud de una enmienda a este artículo presentada en el Congreso de los Diputados por el Grupo Parlamentario Socialista, se aprobó la inclusión del inciso final: "Una vez recibida la información emitirá, en su caso, su parecer y podrá dirigir al Estado las observaciones que estime pertinentes $"{ }^{31}$.

La regulación se completa con la previsión de que la Junta de Andalucía será informada de los proyectos y proposiciones de legislación aduanera, sobre cuya información emitirá, en su caso, su parecer y podrá dirigir al Estado las observaciones que estime pertinentes ${ }^{32}$. Según el párrafo 2, cuando se trate de tratados y convenios que afecten directa y singularmente a la Comunidad Autónoma, la Junta de Andalucía podrá solicitar su participación en las delegaciones negociadoras.

30 El artículo 194 de la Propuesta sobre la Intervención e información en los tratados internacionales incluía una redacción de dudosa constitucionalidad, con el verbo intervenir: "La Junta de Andalucía, en los términos que establezca la legislación del Estado, intervendrá en el proceso de elaboración, modificación y denuncia de Tratados y Convenios internacionales, así como de las negociaciones de adhesión a éstos, que afecten a materias de su específico interés. Asimismo, será informada en tal supuesto de los proyectos y proposiciones de legislación aduanera. Una vez recibida la información, el Consejo de Gobierno emitirá en su caso su parecer.

${ }^{31}$ Cfr. Boletín Oficial de las Cortes Generales Congreso de los Diputados VIII Legislatura. Serie B: Proposiciones de Ley 13 de septiembre de 2006. Núm. 246-5. Propuesta de Reforma de Estatuto de Autonomía. Enmiendas e índice e enmiendas al articulado.127/000004, p. 175

32 Según el artículo 211 de la Propuesta de Estatuto. Información sobre tratados y convenios: 1. La Junta de Andalucía será preceptivamente informada por el Estado e intervendrá en el proceso de elaboración, modificación y denuncia de tratados y convenios internacionales que afecten a materias de su específico interés. En tales supuestos será informada asimismo de los proyectos y proposiciones de legislación aduanera. Una vez recibida la información emitirá, en su caso, su parecer. 2. Cuando se trate de tratados y convenios que afecten directa y singularmente a Andalucía, la Comunidad Autónoma podrá solicitar formar parte de las delegaciones negociadoras. El Grupo Parlamentario de Izquierda Unida-Iniciativa per Catalunya Verds presentó una enmienda al articulo 236 en el Congreso de los Diputados, con el siguiente tenor: "1. Andalucía podrá, en el marco de una Ley del Parlamento, celebrar acuerdos en el ámbito internacional de su competencia. 2. Andalucía instará del Estado la delegación de la facultad de negociar tratados internacionales que afecten a materias de su competencia, o que incidan en su territorio(...)». Cfr. Boletín Oficial de las Cortes Generales Congreso de los Diputados VIII Legislatura. Serie B: Proposiciones de Ley 13 de septiembre de 2006. Núm. 246-5. Propuesta de Reforma de Estatuto de Autonomía. Enmiendas e índice e enmiendas al articulado.127/000004, p. 65. 
Otras relaciones de la Junta de Andalucía con el Estado previstas en el nuevo Estatuto son las siguientes:

1) La Junta de Andalucía podrá solicitar del Estado la celebración de tratados internacionales en materias de su competencia.

2) La Comunidad Autónoma adoptará las medidas necesarias para la ejecución de los tratados y convenios internacionales en lo que afecten a las materias atribuidas a su competencia, según el presente Estatuto.

3) La Junta de Andalucía, para la promoción de los intereses andaluces, podrá suscribir acuerdos de colaboración en el ámbito de sus competencias. Con tal fin, los órganos de representación exterior del Estado prestarán el apoyo necesario a las iniciativas de la Junta de Andalucía (art. 241).

4) La Junta de Andalucía participará en los organismos internacionales en asuntos de singular relevancia para la Comunidad Autónoma en el seno de la delegación española (art. 242). Podrá hacerlo directamente cuando así lo permita la normativa estatal ${ }^{33}$.

5) Sobre relaciones culturales con otros Estados, la Comunidad Autónoma podrá solicitar del Gobierno que celebre y presente, en su caso, a las Cortes Generales, para su autorización, los tratados o convenios que permitan el establecimiento de relaciones culturales con los Estados con los que mantenga particulares vínculos culturales o históricos (art. 243) ${ }^{34}$.

6) Sobre participación en foros y encuentros, la Comunidad Autónoma participará en los foros y encuentros de colaboración entre el Estado español y los países fronterizos con Andalucía ${ }^{35}$.

${ }^{33}$ Según la Propuesta de Estatuto, en su artículo 213. Participación en organismos internacionales: "La Junta de Andalucía participará en los organismos internacionales en asuntos relevantes para la Comunidad Autónoma, directamente cuando lo permita la normativa correspondiente, o en el seno de la delegación española».

${ }^{34}$ Según el artículo 214 de la Propuesta de Estatuto de Autonomía, sobre Relaciones culturales con otros Estados: "La Comunidad Autónoma podrá solicitar del Gobierno que celebre y presente, en su caso, a las Cortes Generales, para su autorización, los tratados o convenios que permitan el establecimiento de relaciones culturales con los Estados con los que mantengan particulares vínculos culturales o históricos".

${ }^{35}$ En la Propuesta de Estatuto se contenía un artículo independiente: Artículo 216, Participación en foros y encuentros: "La Comunidad Autónoma participará en los foros y encuentros de colaboración entre el Estado español y los países fronterizos con Andalucía». 
C) Relaciones normativas.- En la fase descendente del Derecho Comunitario europeo el nuevo Estatuto regula una serie de relaciones normativas o "entre ordenamientos" que ni son "institucionales" ni debieron ubicarse en este Título IX. Así, el artículo 235.1 dispone sobre el "Desarrollo y aplicación del derecho de la Unión Europea" que la Junta de Andalucía desarrolla y ejecuta el derecho de la Unión Europea en las materias de su competencia, de acuerdo con lo que establezca una ley del Parlamento de Andalucía ${ }^{36}$. Y según el art. 235.2, "en el caso de que la Unión Europea establezca una legislación que sustituya a la normativa básica del Estado, la Junta de Andalucía podrá adoptar la legislación de desarrollo a partir de las normas europeas".

D) La cooperación al desarrollo.- Una de las grandes novedades del Estatuto consiste en dedicar un Capítulo $\mathrm{V}$ a la Cooperación al desarrollo, competencia fundamentada en el principio de solidaridad (art. 245), que se atribuye al pueblo andaluz, como sujeto que "participa de la solidaridad internacional con los países menos desarrollados promoviendo un orden internacional basado en una más justa redistribución de la riqueza". Con tal fin, la Comunidad Autónoma de Andalucía, bajo la coordinación de la Dirección General de Asuntos Europeos y Cooperación Exterior (Decreto 61/1995, de 14 de marzo) y la Agencia Andaluza de Cooperación Internacional, despliega actividades de cooperación al desarrollo en dichos países, dirigidas a la erradicación de la pobreza, la defensa de los derechos humanos y la promoción de la paz y los valores democráticos ${ }^{37}$, particularmente en lberoamérica, el Magreb y el conjunto de África. Según el párrafo 3, serán también objeto de atención preferente las políticas de cooperación al desarrollo con países vecinos o culturalmente próximos, o que se concierten con Estados receptores de emigrantes andaluces o de procedencia de inmigrantes hacia Andalucía.

Un precepto se dedica asimismo a la cooperación interregional y transfronteriza (art. 246): la Junta de Andalucía promoverá la formalización

36 El artículo 205. Aplicación y ejecución de la normativa comunitaria, de la Propuesta de Estatuto disponía en redacción casi identifica: "Corresponde a los poderes públicos andaluces el desarrollo y ejecución del derecho de la Unión Europea en las materias de su competencia, de acuerdo con lo que establezca una ley del Parlamento de Andalucía».

37 El inciso "y los valores democráticos" fue resultado de una enmienda del GPP al artículo 217 de la Propuesta de Estatuto, con la siguiente justificación: La inclusión de la denominada condición política de respeto a los valores democráticos es inherente a las más recientes aportaciones doctrinales de la teoría de la cooperación internacional, y discrimina positivamente los esfuerzos democratizadores de los Estados destinatarios de los fondos de cooperación internacional. 
de convenios y acuerdos interregionales y transfronterizos con regiones y comunidades vecinas en el marco de lo dispuesto en la Constitución, los Estatutos de Autonomía y la normativa europea de aplicación ${ }^{38}$.

El capítulo sobre cooperación finaliza con el artículo 247, relativo a la coordinación de la acción exterior en materia de cooperación, según el cual la Junta de Andalucía impulsa y coordina las acciones exteriores de las Corporaciones locales, de los organismos autónomos y de otros entes públicos de Andalucía en materia de cooperación exterior, respetando la autonomía que en cada caso corresponda.

E) Otras relaciones.- Desubicado sistemáticamente aparece el art. 237, sobre "Consulta al Parlamento de Andalucía", precepto que dispone: «El Parlamento de Andalucía será consultado previamente a la emisión del dictamen de las Cortes Generales sobre las propuestas legislativas europeas en el marco del procedimiento de control del principio de subsidiariedad y proporcionalidad que establezca el derecho comunitario" 39 . Por su parte, el artículo 239, sobre las "Relaciones con las regiones europeas" afirma que "la Junta de Andalucía promoverá la cooperación, y establecerá las relaciones que considere convenientes para el interés general de Andalucía, con las regiones europeas con las que comparta objetivos e intereses" ${ }^{40}$ y que "los poderes públicos de

38 La siguiente enmienda al articulado fue presentada en el Congreso de los Diputados por el Grupo Parlamentario Vasco. Artículo 233 bis. Andalucía como frontera sur de la Unión Europea. Andalucía como territorio fronterizo europeo tendrá un régimen especial de cooperación con la Unión Europea..... (...)». Cfr. Boletín Oficial de las Cortes Generales Congreso de los Diputados VIII Legislatura. Serie B: Proposiciones de Ley 13 de septiembre de 2006. Núm. 246-5. Propuesta de Reforma de Estatuto de Autonomía. Enmiendas e índice e enmiendas al articulado.127/000004, p. 99. Según la LO 6/2006, en su Artículo 197. Cooperación Transfronteriza, Interregional y al Desarrollo, 1. La Generalitat debe promover la cooperación con las regiones europeas con las que comparte intereses económicos, sociales, ambientales y culturales, y debe establecer las relaciones que correspondan. 2. La Generalitat debe promover programas de cooperación al desarrollo. 3. La Generalitat debe promover programas de cooperación al desarrollo.

39 Una enmienda al artículo 233 presentada en el Congreso de los Diputados por el Grupo Parlamentario Socialista solicitó sustituir "establece" por "establezca». Cfr. Boletín Oficial de las Cortes Generales Congreso de los Diputados VIII Legislatura. Serie B: Proposiciones de Ley 13 de septiembre de 2006. Núm. 246-5. Propuesta de Reforma de Estatuto de Autonomía. Enmiendas e índice e enmiendas al articulado.127/000004, p. 175.

40 Más escueta era la Propuesta de Estatuto, que omitía el «interés general de Andalucía» en su artículo 210 Relaciones con regiones europeas: "Andalucía promoverá la cooperación, y establecerá las relaciones que considere convenientes, con las regiones europeas con las que comparta objetivos e intereses". 
Andalucía impulsarán la presencia de las regiones en la definición de las políticas de la Unión Europea».

\section{LAS RELACIONES CON EL ESTADO}

El art. $10.9^{\circ}$ del nuevo texto estatutario determina que uno de los objetivos de la Comunidad Autónoma reside en la convergencia con el resto del Estado y de la Unión Europea, promoviendo y manteniendo las necesarias relaciones de colaboración con el Estado (...) lo que se une a la necesaria satisfacción, en el artículo 6, del derecho de los andaluces en el exterior y las comunidades andaluzas asentadas fuera de Andalucía "a participar en la vida del pueblo andaluz». Con este fin, el Título IX, sobre Relaciones institucionales, reserva el Capítulo I a las relaciones con el Estado, articuladas «de acuerdo con lo que establezcan en cada caso la Constitución, la legislación del Estado y la normativa de la Unión Europea» (art. 218) y a partir de los principios establecidos en el art. 219.1, un precepto que, en primer lugar, erige al principio de solidaridad en referencia de reguladora de las relaciones con el Estado, en segundo lugar, omite el principio de coordinación presente en el artículo 103.1 CE y, en tercer lugar, distingue la colaboración de la cooperación, sin que sepamos las razones jurídicas de esta diferenciación: "En el marco del principio de solidaridad las relaciones de la Comunidad Autónoma de Andalucía con el Estado se fundamentan en la colaboración, cooperación, lealtad institucional y mutuo auxilio» (art. 219) ${ }^{41}$.

Pues bien, en este marco de principios presidido por la solidaridad, el párrafo 2 regula una de las grandes novedades de las reformas estatutarias — nuevos Estatutos- de Andalucía y Cataluña: el principio de bilateralidad y sus consecuencias orgánicas y decisorias: "Para los asuntos de interés específico de la Comunidad Autónoma se establecerán los correspondientes instrumentos bilaterales de relación. En los asuntos de interés general, Andalucía participará a través de los procedimientos o en los órganos multilaterales que se constituyan". Una bilateralidad, con reconocimiento orgánico en la Comisión Bilateral Junta de Andalucía-Estado, que se ha convertido, por motivos políticos y por las dudas de constitucionalidad que suscita la indefinición de su régimen jurídico y la posibilidad de su conversión en principio general de las relaciones Estado-Comunidades Autónomas, en uno de los contenido más polémicos de la reforma estatutaria, tanto en Andalucía como en Cataluña; polémica que sin duda ha contribuido, en la fase de

${ }^{41}$ Originario artículo 188 de la Propuesta. 
enmiendas en el Congreso, a una corrección sustancial de la impronta confederal de esta técnica ${ }^{42}$. En este contexto de principios, las relaciones entre la Junta de Andalucía y el Estado pueden ser clasificadas en atención a su objeto (relaciones propiamente institucionales: función representativa del Presidente de la Junta, participación en órganos constitucionales, relaciones normativas, relaciones con futuros territorios andaluces, relaciones financieras) y en atención a los sujetos que intervienen en ellas (relaciones estrictamente intergubernamentales: relaciones bilaterales y relaciones multilaterales).

A) Por el objeto de las relaciones:

1) Relaciones institucionales del Presidente de la Junta de Andalucía en el marco de su función representativa.-De esta función del Presidente de la Junta de Andalucía, cuya regulación en este Título parece innecesaria porque ya está presente en otras partes del Estatuto, Ilama la atención que la representación institucional de la Junta de Andalucía se relegue al final del Capítulo I del Título IX del nuevo Estatuto, pese a su reconocimiento constitucional (art. $152 \mathrm{CE}$ ) y estatutario (art. 73 la LO 6/1981 y art. 117 del nuevo Estatuto: "ostenta la suprema representación de la Comunidad Autónoma y la ordinaria del Estado en Andalucía») y a su relevancia simbólica, jurídica, política y protocolaria. Según el artículo 229, sobre la representación de la Comunidad Autónoma, corresponde al Presidente de la Junta la representación de la Comunidad Autónoma de Andalucía en sus relaciones con el Estado.

2) Participación en órganos constitucionales ${ }^{43}$.-Según el artículo 223, los Senadores elegidos o designados por Andalucía podrán comparecer ante el Parlamento en los términos que establezca su Reglamento para informar de su actividad en el Senado ${ }^{44}$. Según el art. 224,

42 En el Título V, Capítulo I, Sección primera, sobre Colaboración con el Estado y con otras Comunidades Autónomas, el artículo 175 de la LO 6/2006, dispone sobre "Instrumentos de colaboración entre la Generalitat y el Estado»:1. La Generalitat y el Estado, en el ámbito de las competencias respectivas, pueden suscribir convenios de colaboración y hacer uso de los otros medios de colaboración que consideren adecuados para cumplir los objetivos de interés común (...).

${ }^{43}$ Cfr. I. LASAgabasteR, "Relaciones intergubernamentales y Federalismo Cooperativo", Revista Vasca de Administración Pública 41, 1995, pp. 203-220; D.S. WRIGHT, D.S., «Del federalismo a las relaciones intergubernamentales en los Estados Unidos de América: una nueva perspectiva de la actuación recíproca entre el gobierno nacional, estatal y local, Revista de Estudios Políticos 6, 1978, pp. 5-28, y D. WRIGHT, Understanding Intergovernmental Relations. California, Brooks/Cole, Belmont, 1988.

44 En la redacción originaria de la Propuesta se incluía un inciso final de remisión al reglamento parlamentario andaluz: Artículo 192. Senadores por Andalucía: 
la Junta de Andalucía participará en los procesos de designación de los órganos constitucionales en los términos que dispongan las leyes o, en su caso, el ordenamiento parlamentario ${ }^{45}$.

3) Relaciones normativas.-Según la Disposición transitoria segunda. Vigencia de leyes y disposiciones del Estado: «Mientras las Cortes Generales no elaboren las leyes a que este Estatuto se refiere y el Parlamento de Andalucía legisle sobre las materias de su competencia, continuarán en vigor las actuales leyes y disposiciones del Estado que se refieren a dichas materias, sin perjuicio de que su desarrollo legislativo, en su caso, y su ejecución se lleven a cabo por la Comunidad Autónoma en los supuestos así previstos en este Estatuto". En este ámbito normativo de las relaciones con el Estado, debe recordarse, como ya ocurría con al Estatuto de 1981, que la utilización o no del procedimiento agravado de reforma estatutaria viene determinado por la no afectación a las relaciones Estado-Junta de Andalucía (art. 245): "Cuando la reforma no afectara a las relaciones de la Comunidad Autónoma con el Estado, se podrá proceder de la siguiente manera (...) ${ }^{46}$.

"Los senadores elegidos o designados por Andalucía podrán comparecer ante el Parlamento para informar de su actividad en el Senado en los términos que establezca el Reglamento del Parlamento de Andalucía».

45 El texto aprobado en el Parlamento de Andalucía preveía la participación en los órganos constitucionales y en las instituciones del Estado, de acuerdo con lo previsto en el presente Estatuto y atendiendo a los procedimientos que para la designación de los miembros de los mismos establezca la legislación estatal, y, además, la Junta de Andalucía participará en los procesos de designación de Magistrados del Tribunal Constitucional y de miembros de Consejo del Poder Judicial. La redacción originaria de la Propuesta, en el artículo 193, no incluía la remisión a lo "previsto en el presente Estatuto", resultado de las enmiendas en el Parlamento de Andalucía. Participación en las instituciones del Estado: "Andalucía participará en los órganos constitucionales y en las instituciones del Estado de acuerdo con los procedimientos que para la designación de sus miembros establezca la legislación estatal».En la Sección segunda. Participación en instituciones y en procedimientos de toma de decisiones estatales, el artículo 179. Comparecencia de senadores ante el Parlamento, dispone que "Los Senadores elegidos en Cataluña y los que representan a la Generalitat en el Senado pueden comparecer ante el Parlamento a petición propia para informar sobre su actividad en el Senado, en los términos que establece el Reglamento del Parlamento".

46 Según el artículo 64 de la LORAFNA, en su Título II. Capítulo IV. Relaciones con la Administración del Estado: «En virtud de lo establecido en el párrafo primero de la disposición adicional primera de la Constitución y en el artículo 2 de la presente Ley, las relaciones entre la Administración del Estado y la Comunidad Foral referentes a sus respectivas facultades y competencias, se establecerán conforme a la naturaleza del régimen foral y deberán formalizarse, en su caso, mediante una disposición del rango que corresponda (...). 
Por otra parte, en lo relativo a las relaciones normativas derivadas de la ley orgánica del artículo $150.2 \mathrm{CE}$, hemos de destacar la aprobación de la enmienda de supresión presentada en el Congreso de los Diputados por varios grupos parlamentarios, basada en la inconstitucionalidad del texto aprobado en el Parlamento de Andalucía como Disposición adicional cuarta. Transferencia y delegación adicional de competencias.1. "Al amparo del artículo 150.2 de la Constitución, la Comunidad Autónoma de Andalucía asume, mediante transferencia o de legación, las facultades de ejecución de competencia del Estado en las siguientes materias (...)». Según la justificación de la enmienda del Grupo Parlamentario Socialista del Congreso: "Un Estatuto de Autonomía no puede incluir ningún precepto que pretenda que una Comunidad Autónoma asuma facultades de competencia estatal a través de la vía del artículo 150.2 de la Constitución (...) ${ }^{47}$.

4) Relaciones con futuros territorios andaluces.-Según la muy voluntarista Disposición adicional primera, sobre Territorios históricos, la ampliación de la Comunidad Autónoma a territorios históricos no integrados en otra Comunidad Autónoma se resolverá por las Cortes Generales, previo acuerdo de las partes interesadas y sin que ello suponga reforma del presente Estatuto, una vez que dichos territorios hayan vuelto a la soberanía española.

5) Relaciones financieras.-Según el artículo 183, sobre las relaciones financieras de la Comunidad Autónoma con la Administración del Estado, las relaciones de la Comunidad Autónoma con el Estado en materia financiera se regirán por los principios transparencia, lealtad institucional y participación en las decisiones que les afecten; en el Congreso de los Diputados se eliminaron los principios de igualdad y responsabilidad fiscal, presentes en otros preceptos. Según el párrafo 2, Andalucía, atendiendo a sus intereses en materia de financiación, podrá decidir libremente su vinculación al modelo de financiación autonómica en el modo y forma previstos en el artículo 184, respetándose los principios generales de la Hacienda de la Comunidad Autónoma (art. 175). Por su parte, según el párrafo 183. 3, Andalucía colaborará o participará, en la forma que determine la normativa aplicable, en la gestión de la Agencia Tributaria estatal. Según el párrafo 4, ambas Administraciones se facilitarán mutuamente el acceso a la información estadística y de gestión necesaria para el ejercicio de sus respectivas competencias

47 Cfr. Boletín Oficial de las Cortes Generales Congreso de los Diputados VIII Legislatura. Serie B: Proposiciones de Ley 13 de septiembre de 2006. Núm. 246-5. Propuesta de Reforma de Estatuto de Autonomía. Enmiendas e índice e enmiendas al articulado.127/000004, p. 176. 
en un marco de cooperación y transparencia, lo que se completa en el párrafo 5, para el caso de reforma o modificación del sistema tributario español que implique una supresión de tributos o una variación de los ingresos de la Comunidad Autónoma de Andalucía, que dependen de los tributos estatales, la Comunidad Autónoma de Andalucía tiene derecho a que el Estado adopte las medidas de compensación oportunas para que ésta no vea reducidas ni menguadas las posibilidades de desarrollo de sus competencias ni de su crecimiento futuro. De acuerdo con el principio de lealtad institucional, se valorará el impacto financiero, positivo o negativo, que las disposiciones generales aprobadas por el Estado tengan sobre la Comunidad Autónoma o las aprobadas por la Comunidad Autónoma tengan sobre el Estado, en un periodo de tiempo determinado, en forma de una variación de las necesidades de gasto o de la capacidad fiscal, con la finalidad de establecer los mecanismos de ajuste necesarios.

Por último, según el párrafo 6, Andalucía participará en la forma en que se determine, en la realización de los estudios, análisis, informes o cualquier otro tipo de actuación que se estime precisa en materia de regulación, aplicación de los tributos cedidos a las Comunidades Autónomas.

B) Por los sujetos de las relaciones:

B.1. Relaciones bilaterales ${ }^{48}$._-Las relaciones bilaterales se articulan a través de la Comisión Bilateral de Cooperación Junta de AndalucíaEstado y las Comisiones Mixtas, siendo prevista estatutariamente la Comisión de Asuntos Económicos y Fiscales Estado-Comunidad Autónoma.

B.1.1. La Comisión Bilateral de Cooperación Junta de Andalucía-Estado.-Según el párrafo 220. 1: «Se creará una Comisión Bilateral Junta de Andalucía-Estado " ${ }^{49}$, de acuerdo con los principios establecidos

48 Según el originario artículo 189, se empleaba la forma verbal de presente: "que constituye el marco general y permanente de relación entre Andalucía y el Estado a los siguientes efectos: a) La participación, información, colaboración y coordinación en el ejercicio de las competencias estatales que afecten a la autonomía de Andalucía; b) El establecimiento de mecanismos de información y colaboración acerca de las respectivas políticas públicas y los asuntos de interés común; c) La fijación del alcance y condiciones de la cesión de lo tributos a que se refiere el art. 153; y d) El impulso de la eficacia, el seguimiento y la resolución de conflictos en todas las cuestiones de interés común.

49 La enmienda al Título IX, presentada en el Congreso de los Diputados por el Grupo Parlamentario Popular, contiene una redacción alternativa al Título IX, que re- 
en el artículo 219, ya mencionados, que "constituirá el marco general y permanente de relación entre los Gobiernos de la Junta de Andalucía y del Estado» ${ }^{50}$. La Comisión Bilateral se creó el día 9 de abril de 2007 con el siguiente ámbito competencial:

a) La participación, información, colaboración y coordinación en el ejercicio de sus respectivas competencias, previstas en el art. 220.2.

b) El establecimiento de mecanismos de información y colaboración acerca de las respectivas políticas públicas y los asuntos de interés común.

Presidida por el Ministro de Administraciones Públicas, la Comisión Bilateral está compuesta por los secretarios de Estado de Hacienda y Presupuestos, y de Cooperación Territorial en la representación estatal, y, en la representación autonómica, por los consejeros de la Presidencia, de Gobernación, de Economía y Hacienda, y Justicia y Administración Pública, así como por el Viceconsejero de Presidencia. La Comisión de organiza en tres subcomisiones (Subcomisión de Ordenación y Planificación de Traspasos, Subcomisión de Cooperación y Colaboración, y Subcomisión de Prevención de conflictos y Controversias Competenciales) y varios grupos de trabajo, y ha aprobado el establecimiento de un reglamento de la misma y la definición de un método de trabajo, con una primera fase dedicada a tratar la metodología que servirá para analizar las futuras inversiones estatales en An-

gula la denominada Comisión de Cooperación Estado-Junta de Andalucía, cuyo régimen jurídico «meramente consultivo» se remite al artículo 5.1 de la Ley 30/1992. También incluye el calificado como "marco general de proyección» externa de Andalucía. En la justificación de la enmienda se afirma que «El principio de bilateralidad inspira la redacción de esta reforma estatutaria. Como consecuencia de ello, este Estatuto insiste en el cambio esencial en el modelo de Estado, sustituyendo el modelo cooperativo propio del Estado Autonómico por otro de naturaleza dual, lo que transforma el modelo de organización política hacia fórmulas de corte confederal». Cfr. Boletín Oficial de las Cortes Generales Congreso de los Diputados VIII Legislatura. Serie B: Proposiciones de Ley 13 de septiembre de 2006. Núm. 246-5. Propuesta de Reforma de Estatuto de Autonomía. Enmiendas e índice e enmiendas al articulado.127/000004, pp. 156-157.

50 Véase la Sección tercera, sobre la Comisión Bilateral Generalitat - Estado, de la LO 6/2006, que dispone en su artículo 183, sobre funciones y composición de la Comisión Bilateral Generalitat- Estado: 1. La Comisión Bilateral Generalitat-Estado, de acuerdo con los principios establecidos por los artículos 3.1 y 174 , constituye el marco general y permanente de relación entre los Gobiernos de la Generalitat y el Estado a los siguientes efectos: a) La participación y la colaboración de la Generalitat en el ejercicio de las competencias estatales que afecten a la autonomía de Cataluña;(...).. 
dalucía, en cumplimiento de lo establecido en la Disposición Adicional Tercera del Estatuto de Andalucía. De acuerdo con lo establecido en el Estatuto de autonomía para Andalucía, la presidencia de la Comisión se alternará anualmente.

Según el art. 220.2, las funciones de la Comisión Bilateral Junta de Andalucía-Estado son deliberar, hacer propuestas y, si procede, adoptar acuerdos en los casos establecidos expresamente por el Estatuto y, en general, con relación con los siguientes ámbitos ${ }^{51}$ :

a) Los proyectos de ley que inciden singularmente sobre la distribución de competencias entre el Estado y la Junta de Andalucía.

b) La programación de la política económica general del Gobierno del Estado en todo aquello que afecte singularmente a los intereses y las competencias de la Comunidad Autónoma de Andalucía y sobre la aplicación y el desarrollo de esta política ${ }^{52}$.

c) El impulso de las medidas adecuadas para mejorar la colaboración entre el Estado y la Comunidad Autónoma de Andalucía y asegurar un ejercicio más eficaz de las competencias respectivas en los ámbitos de interés común.

d) Los conflictos competenciales planteados entre las dos partes y la propuesta, si procede, de medidas para su resolución.

e) La evaluación del funcionamiento de los mecanismos de colaboración que se hayan establecido entre el Estado y la Comunidad

51 Según la Disposición adicional tercera. Inversión del Estado en Andalucía: 1. El gasto de inversión del Estado con destino a Andalucía deberá garantizar de forma efectiva el equilibrio económico territorial, en los términos del artículo 138.1 y 2 de la Constitución. 2. La garantía de dicho equilibrio supone que la inversión destinada a Andalucía sea al menos equivalente al peso de la población andaluza sobre el conjunto del Estado. Según la Disposición adicional cuarta. Transferencia y delegación adicional de competencias.1. Al amparo del artículo 150.2 de la Constitución, la Comunidad Autónoma de Andalucía asume, mediante transferencia o delegación, las facultades de ejecución de competencia del Estado en las siguientes materias: a) Puertos y aeropuertos de interés general; b) Servicio meteorológico en Andalucía; c) Cuenca Hidrográfica del Guadalquivir (...).

${ }^{52}$ En este ámbito debe destacarse que, según la Disposición adicional segunda, sobre Asignaciones complementarias. 1. Dadas las circunstancias socioeconómicas de Andalucía, que impiden la prestación de un nivel mínimo en alguno o algunos de los servicios efectivamente transferidos, los presupuestos generales del Estado consignarán, con especificación de su destino y como fuentes excepcionales de financiación, unas asignaciones complementarias para garantizar la consecución de dicho nivel mínimo (...). 
Autónoma de Andalucía y la propuesta de las medidas que permitan mejorarlo.

f) La propuesta de la relación de organismos económicos, instituciones financieras y empresas públicas del Estado en los que la Comunidad Autónoma de Andalucía puede designar representantes, y las modalidades y las formas de esta representación.

g) El seguimiento de la política europea para garantizar la efectividad de la participación de la Comunidad Autónoma de Andalucía en los asuntos de la Unión Europea.

h) El seguimiento de la acción exterior del Estado que afecte a las competencias propias de la Comunidad Autónoma de Andalucía.

i) Las cuestiones de interés común que establezcan las leyes o que planteen las partes.

j) La modificación del régimen especial agrario en su proyección en Andalucía, así como los aspectos que afecten directamente al empleo rural y a la determinación, cuantificación y distribución de los fondos dirigidos al mismo.

Especial interés presentaba la competencia reconocida en el párrafo 6, suprimido en el trámite de enmiendas en el Congreso de los Diputados, según el cual la calificación de interés general por la regulación estatal de cualquier obra, servicio o adquisición requerirá la participación e informe previo de la Comunidad Autónoma de Andalucía o, en su caso, de la Comisión Bilateral prevista en este artículo; según el tenor literal del párrafo eliminado, "se podrán establecer mecanismos de gestión directa de la Comunidad Autónoma o compartida respecto a tales obras o servicios" ${ }^{53}$.

En cuanto a su composición y funcionamiento, la Comisión Bilateral Junta de Andalucía- Estado está integrada por un número igual de representantes del Estado y de la Junta de Andalucía, siendo su presidencia ejercida de forma alternativa entre las dos partes en turnos de un año (art. 220.3). La Comisión dispone de una secretaría permanente, puede crear las subcomisiones y los comités que crea convenientes y debe elaborar una memoria anual, que traslada al Gobierno del Estado y al Gobierno de la Junta de Andalucía y al Parlamento ${ }^{54}$.

53 Según el art. 189.3 de la Propuesta de Estatuto.

54 El recurso de inconstitucionalidad del Partido Popular, en relación con el Capítulo I (Relaciones de la Generalitat con el Estado y con otras Comunidades Autónomas) y, en particular, sobre el artículo 174.3 dice: Es inaceptable constitucional- 
Por último, la Comisión Bilateral Junta de Andalucía Estado se reúne en sesión plenaria al menos dos veces al año y siempre que lo solicite una de las dos partes (art. 220.4), adoptado su reglamento interno y de funcionamiento por acuerdo de las dos partes ${ }^{55}$.

B.1.2. La Comisión Mixta de Asuntos Económicos y Fiscales Estado-Comunidad Autónoma.-En virtud del artículo 184, la Comisión Mixta de Asuntos Económicos y Fiscales Estado-Comunidad Autónoma, creada el día 7 de mayo de 2007, es el órgano bilateral de relación entre el Estado y la Comunidad Autónoma en el ámbito de la financiación autonómica. Le corresponde la concreción, aprobación, actualización y el seguimiento del sistema de financiación, así como la canalización del conjunto de relaciones fiscales y financieras de la Comunidad Autónoma y el Estado, y ejercerá sus funciones sin perjuicio de los acuerdos suscritos por la Junta de Andalucía en esta materia en instituciones y organismos de carácter multilateral. Según la Disposición final segunda, la Comisión Mixta de Asuntos Económicos y Fiscales del Estado-Comunidad Autónoma debe crearse en el plazo máximo de seis meses desde la entrada en vigor del presente Estatuto. Mientras no se constituya, la Comisión Mixta Paritaria Gobierno-Junta de Andalucía prevista en la Disposición Transitoria Primera, asume sus competencias, y en tanto ésta se constituye, asumirá esas competencias la Comisión Mixta de Transferencias Administración del Estado-Comunidad Autónoma.

La Comisión Mixta estará integrada por un número igual de representantes del Estado y de la Comunidad Autónoma. La presidencia de la misma será ejercida de forma rotatoria entre las dos partes en turnos anuales. Según el párrafo 3, la Comisión Mixta adoptará su reglamento interno y de funcionamiento por acuerdo entre las dos delegaciones. Corresponde a la Comisión Mixta de Asuntos Económicos y Fiscales Estado-Comunidad Autónoma: a) Acordar el alcance y condiciones de la cesión de tributos de titularidad estatal y, especialmente, los porcentajes de participación en el rendimiento de los tributos es-

mente el apartado 3 del citado artículo, que señala que «la Generalidad debe participar en las instituciones, los organismos y los procedimientos de toma de decisiones del Estado que afecten a sus competencias de acuerdo con lo establecido en el presente Estatuto y la correspondiente legislación orgánica.",. Recurso, ibidem.

55 Durante la tramitación en el Parlamento de Andalucía, se añadió el calificativo de "plenaria" y la previsión de una secretaría permanente. Según el art. 189.2 de la Propuesta de Estatuto, se disponía que "La Comisión Bilateral Junta de AndalucíaEstado se reunirá al menos dos veces al año. Dicha Comisión podrá crear las subcomisiones o comités que considere convenientes y elaborará una memoria anual que trasladará al Gobierno del Estado y al Parlamento de Andalucía». 
tatales cedidos parcialmente; b) Establecer los mecanismos de colaboración entre la Administración Tributaria de Andalucía y la Administración Tributaria del Estado, así como los criterios de coordinación y de armonización fiscal de acuerdo con las características o la naturaleza de los tributos cedidos; c) Negociar el porcentaje de participación de Andalucía en la distribución territorial de los fondos estructurales europeos; d) Estudiar las inversiones que el Estado realizará en las Comunidad Autónoma de Andalucía; e) Acordar la valoración de los traspasos de servicios del Estado a la Comunidad Autónoma; f) Establecer los mecanismos de colaboración entre la Comunidad Autónoma y la Administración General del Estado que sean precisos para el adecuado ejercicio de las funciones de revisión en vía económico-administrativa; g) Acordar los mecanismos de colaboración entre la Comunidad Autónoma y el Estado para el ejercicio de las funciones en materia catastral. Finalmente, según el apartado 5, la Comisión Mixta propondrá las medidas de cooperación necesarias para garantizar el equilibrio del sistema de financiación que establece el presente Capítulo cuando pueda verse alterado por decisiones legislativas estatales o de la Unión Europea.

Entre todas estas funciones destaca la regulada en Disposición adicional segunda 2 y 3 , sobre asignaciones complementarias o relativas a la denominada "deuda histórica" de la disposición adicional segunda del Estatuto de 1981, en virtud de la cual, si a la fecha de aprobación del nuevo Estatuto, no han sido determinadas y canceladas en su totalidad las cuantías acordadas, la Comisión Mixta establecerá, en el plazo de dieciocho meses, los criterios, alcance y cuantía que conduzcan a la ejecución definitiva del mismo. En este supuesto, la aplicación de los acuerdos adoptados se realizará en un plazo de tres años a partir de la entrada en vigor del presente Estatuto.

Además, según la Disposición final primera, sobre la aplicación de los preceptos de contenido financiero, la Comisión Mixta de Asuntos Económicos y Fiscales del Estado-Comunidad Autónoma de Andalucía debe concretar, en el plazo de dos años a partir de la entrada en vigor del presente Estatuto, la aplicación de los preceptos de contenido financiero del mismo. Los preceptos de contenido financiero del presente Estatuto, salvo que se estableciese un plazo determinado, pueden aplicarse de forma gradual atendiendo a su viabilidad financiera. En todo caso, dicha aplicación debe ser plenamente efectiva en el plazo de cinco años a partir de la entrada en vigor del presente Estatuto.

B.1.3. La Comisión de la Disposición adicional tercera, sobre Inversiones en Andalucía.-Según esta Disposición Adicional, el gasto de 
inversión del Estado con destino a Andalucía deberá garantizar de forma efectiva el equilibrio territorial, en los términos del artículo 138.1 y 2 de la Constitución, y la inversión destinada a Andalucía será equivalente al peso de la población andaluza sobre el conjunto del Estado para un período de siete años. Con esta finalidad se constituirá una Comisión integrada por la Administración estatal y autonómica.

B.1.4. La Comisión Mixta Gobierno-Junta de Andalucía y las Comisiones sectoriales para el traspaso de competencias.-En virtud de la Disposición transitoria primera, sobre traspasos de competencias, al mes siguiente de la entrada en vigor del Estatuto, el 26 de marzo de 2007 se designó la Comisión Mixta Paritaria Gobierno-Junta de Andalucía que regulará el proceso, el tiempo y las condiciones de traspaso de las competencias propias de la Comunidad Autónoma, conforme al presente Estatuto. Asimismo, determinará el traspaso de medios personales y materiales necesarios para el ejercicio de tales competencias. Para la elaboración de las propuestas de traspaso a la Comisión Mixta podrán constituirse, como órganos de trabajo, comisiones sectoriales de transferencias. La Comisión Mixta se reunirá a petición del Gobierno o de la Junta, establecerá sus propias normas de funcionamiento y elevará sus acuerdos al Gobierno para su promulgación como real decreto.

B.2. Relaciones multilaterales.-Según el artículo 221, sobre los instrumentos de colaboración, en virtud del cual: la Junta de Andalucía colaborará con el Estado mediante órganos y procedimientos multilaterales en los asuntos de interés común; el Consejo de Gobierno y el Gobierno central, en el ámbito de sus correspondientes competencias, podrán suscribir instrumentos de colaboración adecuados al cumplimiento de objetivos de interés común; la Comunidad Autónoma participará en la planificación de la actividad económica, tanto general como sectorial, especialmente cuando afecte a sectores estratégicos de interés para Andalucía; y, asimismo, la Comunidad Autónoma participará en la planificación de las inversiones del Estado en Andalucía.

El art. 183.7 dispone que la Comunidad Autónoma de Andalucía mantendrá relaciones multilaterales, a través del Consejo de Política Fiscal y Financiera, en las materias que afecten, entre otras, al sistema estatal de financiación, y en la Comisión Mixta de Asuntos Económicos y Fiscales Estado-Comunidad Autónoma en relación con las cuestiones específicas andaluzas. El artículo 222, sobre participación en la planificación, dispone que la Comunidad Autónoma participará en la planificación de la actividad económica, tanto general como sectorial, espe- 
cialmente cuando afecte a sectores estratégicos de Andalucía, de acuerdo con lo previsto en el artículo 131 de la Constitución ${ }^{56}$.

\section{RELACIONES CON LOS ENTES LOCALES}

Las relaciones de la Junta con los entes locales, reguladas en la legislación básica de régimen local y en la legislación autonómica, han sido incluidas en el Estatuto de Autonomía en pleno debate doctrinal y político sobre las propuestas de Pacto Local Andaluz, un pretendido instrumento ordenador de las competencias y la financiación locales que desde hace siete años espera en el limbo jurídico ${ }^{57}$. Considerado el ámbito más dinámico de las relaciones intergubernamentales, al afectar al casi medio millar de entes locales andaluces, de la regulación estatutaria de esta compleja red de vínculos entre el poder autonómico y el poder local esperaban mucho más tanto la Federación Andaluza de Municipios y Provincias como los sectores políticos y representantes sociales más municipalistas de todos cuantos han concurrido para comparecer durante los años 2005 y 2006 ante el Parlamento de Andalucía ${ }^{58}$. No obstante, parece oportuna la decisión estatutaria de remisión

${ }^{56}$ En la fase de enmiendas el Congreso de los Diputados el Grupo Parlamentario Socialista aprobó la enmienda de supresión del artículo 218.2: «Asimismo, la Comunidad Autónoma participará en la planificación de las inversiones del Estado en Andalucía". Cfr. Boletín Oficial de las Cortes Generales Congreso de los Diputados VIII Legislatura. Serie B: Proposiciones de Ley 13 de septiembre de 2006. Núm. 246-5. Propuesta de Reforma de Estatuto de Autonomía. Enmiendas e índice e enmiendas al articulado.127/000004, p. 175; y Propuesta..., BOCG, 246-7, cit., 246-8, p. 288, y cit., p. 339.

57 Cfr. J. FONT y LLOVET, "La reconstrucción jurídica de la autonomía local. Valoración general». Anuario de Gobierno Local 2003. Barcelona, 2004; Pacto Local Andaluz. Propuestas para el desarrollo. Consejería de Gobernación y Justicia, Junta de Andalucía, Sevilla, abril, 1999, 55 p.; MAP, El Pacto Local. Medidas para el desarrollo del Gobierno Local, Madrid, 1999, pp. 173-174, En el Estatuto de Autonomía de Aragón, el Capítulo II del Título III dispone: Capítulo II. Relaciones de la Comunidad Autónoma con las Entidades Locales. Artículo 44. La Administración de la Comunidad Autónoma y las Administraciones locales ajustarán sus relaciones a los principios de información mutua, colaboración, coordinación y respeto a los ámbitos competenciales correspondientes determinados en el presente Estatuto y en la legislación básica del Estado (...).

58 Según la LO 1/2006, del nuevo Estatuto de Valencia, Título VIII. Administración Local. Artículo 63. 1. Las entidades locales comprendidas en el territorio de la Comunitat Valenciana administran con autonomía los asuntos propios, de acuerdo con la Constitución Española y este Estatuto. 2. Las administraciones públicas locales de la Comunitat Valenciana se rigen en sus relaciones por los principios de coordina- 
del Pacto Local a la ley autonómica toda vez que los entes locales, antes de asumir nuevas competencias, aún deben ser rescatados de su tradicional "huida del Derecho Administrativo", ser financiados conforme al principio de suficiencia y ser sometidos a un amplio proceso de modernización de su empleo público, urbanismo y contratación, así como a una regeneración democrática de sus estructuras.

El nuevo texto estatutario, cuyo artículo 10.8 establece como objetivo de la Comunidad la consecución de la cohesión territorial, la solidaridad y la convergencia entre los diversos territorios de Andalucía, como forma de superación de los desequilibrios económicos, sociales y culturales y de equiparación de la riqueza y el bienestar entre todos los ciudadanos, especialmente los que habitan en el medio rural ${ }^{59}$, condiciona estas relaciones a lo dispuesto previamente en su marco regulador, casi todo reproducido de la Constitución y la Ley básica 7/1985, de 2 de abril. Según el artículo 89.1, sobre la estructura territorial, Andalucía se organiza territorialmente en municipios, provincias y demás entidades territoriales que puedan crearse por ley. En el párrafo 2 se dispone que la Administración de la Comunidad Autónoma y las Administraciones locales ajustarán sus relaciones a los principios de información mutua, coordinación, colaboración y respeto a los ámbitos competenciales correspondientes determinados en el presente Estatuto, en la legislación básica del Estado y en la normativa autonómica de desarrollo, con plena observancia de la garantía institucional de la autonomía local reconocida por la Constitución y por la Carta Europea de la Autonomía Local.

Según el artículo 98, una ley de régimen local, en el marco de la legislación básica del Estado, regulará las relaciones entre las instituciones de la Junta de Andalucía y los entes locales, así como las técnicas de organización y de relación para la cooperación y la colaboración entre los entes locales y entre éstos y la Administración de la Comunidad Autónoma, incluyendo las distintas formas asociativas mancomu-

ción, cooperación y colaboración. 3. La Generalitat y los entes locales podrán crear órganos de cooperación, con composición bilateral o multilateral, de ámbito general o sectorial, en aquellas materias en las que existan competencias compartidas, con fines de coordinación y cooperación según los casos (...).

59 Cfr. R. Agranoff, "Marcos para el análisis comparado de las relaciones intergubernamentales", Papeles de Trabajo de Gobierno y Administración Pública. Madrid: Instituto Universitario Ortega y Gasset, 1991; J. MondRAgón RuIz DE LeZAMA, "La Gestión Intergubernamental: Las relaciones Intergubernamentales en España» en OliAs DE LIMA, B. (coord.): La Nueva Gestión Pública. Madrid, Prentice Hall, 2001, pp. 319-335. 
nales $^{60}$, convencionales y consorciales, así como cuantas materias se deduzcan del artículo 60 . Según el párrafo 2, la Ley de régimen local tendrá en cuenta las diferentes características demográficas, geográficas, funcionales, organizativas, de dimensión y capacidad de gestión de los distintos entes locales.

Conforme a un criterio de clasificación por el objeto de las relaciones Junta de Andalucía-entes locales podemos establecer las siguientes categorías de relaciones:

a) Relaciones orgánicas.-Como órgano de relación de la Junta de Andalucía y los Ayuntamientos, el artículo 95 establece que una ley de la Comunidad Autónoma regulará la creación, composición y funciones de un órgano mixto con representación de la Junta de Andalucía y de los Ayuntamientos andaluces, que funcionará como ámbito permanente de diálogo y colaboración institucional, y será consultado en la tramitación parlamentaria de las disposiciones legislativas y planes que afecten de forma específica a las Corporaciones locales.

b) Relaciones financieras.-En cumplimiento del art. $142.2 \mathrm{CE}$, según el artículo 192, sobre la colaboración de la Comunidad Autónoma, una ley regulará la participación de las Entidades Locales — sólo los Ayuntamientos en la redacción del Parlamento de Andalucía- en los tributos de la Comunidad Autónoma, que se instrumentará a través de un fondo de nivelación municipal, de carácter incondicionado. Según el párrafo 2, adicionalmente la Comunidad Autónoma podrá establecer programas de colaboración financiera específica para materias concretas. Según el párrafo 3, corresponde a la Comunidad Autónoma la tutela financiera de los entes locales, sin perjuicio de las competencias del Estado y con respeto a la autonomía que a los mismos les reconoce la Constitución.

A su vez, los entes locales podrán delegar a favor de la Comunidad Autónoma la gestión, liquidación, recaudación e inspección de sus propios tributos o establecer alguna otra forma de colaboración. Los ingresos de los entes locales consistentes en participaciones en ingresos y en subvenciones incondicionadas estatales se percibirán a través de la Comunidad Autónoma, que los distribuirá de acuerdo con los criterios establecidos en sus leyes, respetando los criterios fijados por la legislación del Estado en esta materia. Según el párrafo 6, las modificaciones del marco normativo de la Comunidad Autónoma que

60 El legislador estatuyente no ha acertado a redactar la expresión «fórmulas asociativas mancomunadas" y utiliza una palabra tan incorrecta como la que previamente se contemplaba: mancomunación. 
disminuyan los ingresos tributarios locales habrán de prever la compensación oportuna. Finalmente, el art. 192.7 establece una cláusula de suficiencia financiera: "Cualquier atribución de competencias irá acompañada de la asignación de recursos suficientes".

c) Relaciones con los entes supramunicipales.-El artículo 94, sobre agrupación de municipios, dispone que una ley regulará las funciones de las áreas metropolitanas, mancomunidades, consorcios y aquellas otras agrupaciones de municipios que se establezcan, para lo cual se tendrán en cuenta las diferentes características demográficas, geográficas, funcionales, organizativas, de dimensión y capacidad de gestión de los distintos entes locales ${ }^{61}$.

\section{RELACIONES CON OTRAS COMUNIDADES AUTÓNOMAS Y CON LAS CIUDADES AUTÓNOMAS}

El artículo 229, sobre representación de la Comunidad Autónoma de Andalucía, desarrolla la función institucional representativa que el artículo 152 CE reconoce, como vimos, al Presidente de la Comunidad Autónoma: "la representación de la Comunidad Autónoma de Andalucía en sus relaciones con otras Comunidades Autónomas" ${ }^{62}$. Previamente, con la cobertura constitucional del artículo 145.1 de la CE, el Capítulo II, bajo la rúbrica de "Relaciones con otras Comunidades y Ciudades Autónomas" ${ }^{63}$ dispone en el artículo 226 "Convenios y acuer-

61 El artículo 95. Comarcas, dispone: 1. La comarca se configura como la agrupación voluntaria de municipios limítrofes con características geográficas, económicas, sociales e históricas afines. 2. Por ley del Parlamento de Andalucía podrá regularse la creación de comarcas, que establecerá, también, sus competencias. Se requerirá en todo caso el acuerdo de los Ayuntamientos afectados y la aprobación del Consejo de Gobierno.

62 En el Título II de la LORAFNA, el Capítulo V sobre Convenios y acuerdos de cooperación con las Comunidades Autónomas, dispone en el artículo 70. 1. "Navarra podrá celebrar Convenios con las Comunidades Autónomas para la gestión y prestación de servicios propios correspondientes a materias de su exclusiva competencia. Dichos convenios entrarán en vigor a los treinta días de su comunicación a las Cortes Generales, salvo que éstas acuerden en dicho plazo que, por su contenido, el Convenio debe seguir el trámite previsto en el apartado tercero para los Acuerdos de Cooperación. 2. Navarra podrá celebrar Convenios con la Comunidad Autónoma del País Vasco y con las demás Comunidades Autónomas limítrofes para la gestión y prestación de servicios propios correspondientes a las materias de su competencia (...).

63 En la redacción originaria la Propuesta indicaba la siguiente rúbrica al Capítulo II Relaciones con otras Comunidades Autónomas. La inclusión obedeció a con 
dos de cooperación" ${ }^{64}$ : "en los supuestos, condiciones y requisitos que determine el Parlamento, la Comunidad Autónoma de Andalucía puede celebrar convenios con otras Comunidades Autónomas para la gestión y prestación conjunta de servicios propios de las mismas; en todo caso, el Parlamento dispondrá de mecanismos de control y seguimiento de lo acordado" ${ }^{65}$.

Según párrafo 2, el Parlamento comunicará a las Cortes Generales, a través de su Presidente, la celebración, en su caso, de los convenios previstos en el apartado anterior, que entrarán en vigor a los treinta días de tal comunicación ${ }^{66}$. Si las Cortes Generales o alguna de las Cámaras formularan objeciones en dicho plazo, a partir de la recepción de la comunicación, el convenio deberá seguir el trámite previsto en el apartado siguiente de este artículo. Por último, según el art. 226.3, el Parlamento habrá de solicitar autorización de las Cortes Generales para concertar acuerdos de cooperación con otras Comunidades Autónomas. Compete al Parlamento determinar el alcance, la forma y el contenido de dichos acuerdos ${ }^{67}$.

figuración relacional de Andalucía en el Estado de las Autonomías no puede prescindir de las Ciudades Autónomas de Ceuta y de Melilla (art. 144 y Disp. Transit. 5. ${ }^{\text {a CE). }}$

${ }^{64}$ Según la LO 1/2006, del Estatuto de Valencia, Título V. Relaciones con el Estado y otras Comunidades Autónomas. Artículo 59. 1. La Generalitat, a través del Consell, podrá celebrar convenios de colaboración para la gestión y prestación de servicios correspondientes a materias de su exclusiva competencia, tanto con el Estado como con otras comunidades autónomas (...).

${ }^{65}$ El artículo 196 de la Propuesta disponía: Convenios y acuerdos de cooperación. 1. En los supuestos, condiciones y requisitos que determine el Parlamento, la Comunidad Autónoma puede celebrar Convenios con otras Comunidades para la gestión y prestación conjunta de servicios propios de las mismas. En todo caso el Parlamento dispondrá de mecanismos de control y seguimiento de lo acordado. 2. El Parlamento comunicará a las Cortes Generales, a través de su Presidente, la celebración, en su caso, de los Convenios previstos en el apartado anterior, que entrarán en vigor a los treinta días de tal comunicación (...).

66 Una enmienda al artículo 222 presentada en el Congreso de los Diputados por el Grupo Parlamentario Socialista solicitó sustituir el plazo de treinta por sesenta días. Cfr. Boletín Oficial de las Cortes Generales Congreso de los Diputados VIII Legislatura. Serie B: Proposiciones de Ley 13 de septiembre de 2006. Núm. 246-5. Propuesta de Reforma de Estatuto de Autonomía. Enmiendas e índice e enmiendas al articulado.127/000004, p. 175.

67 En la LO 6/2006, el artículo 178, sobre convenios y acuerdos con otras Comunidades Autónomas dispone que la Generalitat puede suscribir con otras Comunidades Autónomas convenios de colaboración y acuerdos de cooperación. Según el párrafo 2, los convenios y los acuerdos con las demás Comunidades Autónomas pueden acordar, entre otros contenidos, la creación de órganos mixtos y el establecimiento de proyectos, planes y programas conjuntos. En el párrafo 3, se 
Perfecto cumplimiento del principio de publicidad se da en el párrafo 4 incluido durante el trámite de enmiendas en el Congreso: "los convenios y los acuerdos suscritos por la Junta de Andalucía con otras Comunidades Autónomas deben publicarse en el Boletín Oficial de la Junta de Andalucía».

Una especial previsión contiene el artículo 227 sobre los convenios de carácter cultural, según el cual el Consejo de Gobierno podrá suscribir convenios para la celebración de actos de carácter cultural en otras Comunidades y Ciudades Autónomas, especialmente dirigidos a los residentes de origen andaluz ${ }^{68}$.

Por último, el artículo 228, sobre relaciones con Ceuta y Melilla, dispone que la Comunidad Autónoma de Andalucía mantendrá unas especiales relaciones de colaboración, cooperación y asistencia con las Ciudades Autónomas de Ceuta y Melilla, lo cual transforma favorablemente, desde el bloque de la constitucionalidad, las vinculaciones de Andalucía con las ciudades norteafricanas y actualiza la vocación española y europea de estos territorios.

\section{UNA REFLEXIÓN CONCLUSIVA}

Una doble reflexión de constitucionalidad formal y material nos permite concluir la descripción y análisis del nuevo texto estatutario andaluz. Desde un punto de vista formal, la extensa y completa regulación del Título IX (artículos 218-247) sobre Relaciones Institucionales responde a una reclamación doctrinal que desde hace un cuarto de siglo ha venido exigiendo la existencia de un régimen sobre relaciones entre poderes relaciones intergubernamentales- entre los diversos niveles de gobierno: europeo, estatal, autonómico y locales. Una acertada decisión estatutaria que, no obstante, suscita algunas dudas de técnica legislativa porque en el Título IX han sido omitidos contenidos sobre relaciones entre poderes que, con desorden sistemático están presentes en otras partes del Estatuto, a la vez que se mezclan -incluso en un mismo capítu-

establece que la suscripción de convenios y acuerdos sólo requiere la aprobación previa del Parlamento en los casos que afecten a las facultades legislativas. En los demás casos, el Gobierno debe informar al Parlamento de la suscripción en el plazo de un mes a contar desde el día de la firma (...).

68 Según el artículo 212 de la Propuesta de Estatuto: Residentes en el exterior: "La Junta de Andalucía podrá dirigirse al Gobierno de la Nación instándole a la celebración de convenios con terceros países donde residan andaluces y andaluzas para una especial asistencia a los mismos». 
lo- la regulación de relaciones orgánicas junto a relaciones entre normas, las cuales en buena teoría constitucional están presididas por principios propios y diferentes: jerarquía normativa, competencia, seguridad jurídica, etc. en un caso; eficacia, interdicción de la arbitrariedad, responsabilidad, control judicial, etc., en el otro. Desde un punto de vista material, el Estatuto asume de manera indubitada la doctrina constitucional sobre relaciones entre poderes, aunque de manera parcial y defectuosa: el texto estatutario no incorpora el principio de coordinación, presente en la teoría constitucional sobre las relaciones intergubernamentales, que han sido definidas por el Tribunal Constitucional a partir del reconocimiento de unas "potestades de coordinación que persigue la integración de la diversidad de las partes o subsistemas en el conjunto o sistema, evitando contradicciones y reduciendo disfunciones que, de subsistir, impedirían o dificultarían, respectivamente, la realidad misma del sistema" (STC 32/1983). El resto de la doctrina sobre las relaciones intergubernamentales está construida en el nuevo Estatuto sobre la base de los principios de solidaridad, lealtad y colaboración, que es un deber general al que tienen que someterse necesariamente las actuaciones de los poderes públicos, en una suerte de razón y criterio inspirador fundamental, para el correcto funcionamiento del sistema de distribución de competencias(...) que no es preciso justificar en preceptos concretos (FJ 14 18/1982, de 4 de mayo; FJ 2 80/1985, de 4 de julio; FJ 5 17/1991, de 31 de febrero).

En el contenido del Título IX, destaca positivamente la aceptación de los mutiniveles o pluralidad de niveles en las relaciones intergubernamentales, con mayor detalle regulados en el caso del nivel de relaciones entre el Gobierno de la Nación -ahora denominado Gobierno del Estado-y el Gobierno Autonómico, donde se incluyen técnicas de relación orgánica (comisiones) y funcional (convenios), suscitando dudas el principio de bilateralidad, categoría relacional de utilización muy limitada en Derecho comparado - su crítica marcó la evolución desde el federalismo dual al mal federalismo cooperativo-. Sería deseable, antes que la invocación a los conceptos jurídicos indeterminados, al interés general, a los títulos competenciales y a la legislación del Estado, una mejor definición de los ámbitos materiales reservados a la multilateralidad y la bilateralidad, la cual, si se generaliza como una técnica de relación Estado-Comunidad Autónoma sin mayores controles constitucionales y parlamentarios, podría conducir a un nuevo entendimiento del Estado de las Autonomías, ajeno a las tendencias de los más avanzados Estados federales, excesivamente paralizante en el ámbito del proceso de toma de decisiones y próximo a fórmulas de corte confederal. Habrá que esperar a la aplicación real del Estatuto. 
En las relaciones de la Junta de Andalucía con los Entes Locales, podría pensarse que el Estatuto ha olvidado el Pacto Local Andaluz, como instrumento ordenador de las competencias y de la financiación de los entes locales que, como propuesta de atribución de competencias a los Ayuntamientos, desde hace siete años espera en el limbo jurídico pese a las reivindicaciones municipalistas. Sin embargo, en este caso nos parece oportuna la decisión estatutaria de remisión del Pacto Local a la ley autonómica toda vez que los entes locales, antes de asumir nuevas competencias, aún deben ser rescatados de su tradicional "huida del Derecho Administrativo" y ser sometidos a un amplio proceso de modernización de su empleo público, urbanismo y contratación, así como a una reorganización supramunicipal de Andalucía más realista y ordenada en el contexto de un nuevo Plan de Ordenación del Territorio y de la siempre reclamada regeneración democrática de las estructuras locales.

Una reflexión favorable merece, siendo Andalucía un territorio fronterizo, la regulación de la cooperación transfronteriza y la habilitación y coordinación de la actividad de los entes locales en esta materia, aunque quizás hubiera sido más ambicioso un Estatuto que contemplara la situación del Campo de Gibraltar y una previsión del enlace fijo con el Norte de África.

Por último, tanto en lo relativo a las relaciones con el Estado, como con las demás Comunidades Autónomas y con la Unión Europea, la reforma estatutaria quizás encontraría un marco más seguro de actuación tras una reforma constitucional que, con la adecuada sistematización competencial, permitiera conocer, con mínima claridad, cuáles son los distintos niveles competenciales del Estado (europeo, estatal, autonómico y local), cuáles son las competencias que corresponden a cada nivel y cuáles son los principios articuladores del ese sistema competencial: un sistema que actualmente no existe y que, con mejor técnica, algún día habrá de reemplazar a la redacción constitucional de 1978, ajena al desarrollo del bloque de la constitucionalidad y del proceso comunitario europeo.

Constituidas las Comisiones previstas estatutariamente (el día 7 de mayo de 2007, la Comisión Mixta de Asuntos Económicos y Fiscales; el día 26 de marzo de 2007, la Comisión Mixta Paritaria; y el día 9 de abril de 2007, la Comisión Bilateral) queda pendiente la puesta en práctica y la asimilación por los poderes públicos de la cultura de las relaciones institucionales (intergubernamentales), correlato inescindible del principio de descentralización y de los demás principios que rigen la actuación gubernamental y administrativa. Recordemos siempre que, al 
distribuirse nuevamente en el Estatuto las competencias entre el Estado y la Junta de Andalucía, de lo que se trata es de administrar mejor, con mayor cercanía al administrado y conforme a los principios de colaboración y lealtad constitucionales y de racionalidad económica y social, no de vaciar al Estado de competencias. En el logro de este objetivo, la correcta aplicación de la teoría constitucional sobre relaciones intergubernamentales -invoquemos el criterio antiformalista recomendado por el profesor Tomás y Valiente: para comprender las instituciones jurídicas no sólo debe atenderse a la letra de las normas sino a su modo de su ejecución-, permitiría situar a España en el camino de las tendencias constitucionales comparadas, las cuales, en el seno de organizaciones de integración como la Unión Europea, perfeccionan las estructuras estatales en cumplimiento de los principios de integración, lealtad, cooperación, eficacia y servicio al ciudadano.

\section{Title}

THE INTERGOVERNMENTAL RELATIONS IN THE NEW STATUTE OF AUTONOMY OF ANDALUCIA.

\section{Summary}

I. THE INSTITUTIONAL RELATIONSHIPS IN THE NEW STATUTE OF AUTONOMY OF ANDALUCIA. II. THE RELATIONSHIPS WITH FOREIGN AND WITH THE EUROPEAN UNION. II. THE RELATIONSHIPS WITH THE STATE. IV. THE RELATIONSHIPS WITH LOCAL COMMUNITIES. V. THE RELATIONSHIPS WITH OTHER AUTONOMOUS COMMUNITIES. VI. A CONCLUSIVE REFLEXION.

\section{Key words}

Constitutional theory, intergovernmental relations, cooperation, Spain, Andalucia, Autonomous Communities, federalism.

\section{Palabras claves}

Teoría constitucional, relaciones intergubernamentales, España, Andalucía, cooperación, Comunidades Autónomas, federalismo.

\section{Abstract}

The territorial system of 1978 (Tittle VIII) is based on a constitutional principle, according to which it is up to the different territories to start 
and to continue the processes of autonomic and to include in their statutes, through consecutive reforms, theirs respectives issues and level of competences. But while the intergovernmental relations are constantly changing in federal comparative system from half-century ago, the constitutional theory in Spain has not advanced in this matter. Although the Spanish Constitution does not formally create a federation, but the State of Autonomies has led to gradual approachment to Federal State. In Spain, the federal argument is not essential to the debate over the powers of several governments, so the bilateral fiscal and political negotiations between historic communities and the State, but the understanding the impact of intergovernmental relations between the State, autonomic powers and local levels is very important.

In this context, after the referendum of 18 February 2007, called by Decree 2/ 2007, of 16 January, issued by the President of the Autonomous Government, after its publication in the Official State Gazette (BOE) and in the Official Journal of the Autonomous Government of Andalucía (BOJA), the new Statute of Autonomía (Organic Law 2/2007 of 19 March) has came into force, including a new issue: the intergovernmental relations (Tittle IX Institutional relations).

This Organic Law and other laws establish the promotion of collaborative mechanisms in the sectors which have relationships with the State, with others Autonomous Communities, with the local levels and with the European Communities, in which the competences of the these public administrations might converge. Literally hundreds of convenios de colaboración cut across numerous domestic arenas; agriculture, fisheries and fishing, health, social services, labor, culture, and many more. These convenios bring together central, autonomies and sometimes local officials to work out issues. There are also sectoral conferences, comprised of central ministers and autonomics ministers, to discuss major issues within their area, e.g. in environment, public works, tourism, culture, education... Also a Conference of Presidents brings together the First Minister and Presidents of Autonomies.

All of these mechanisms are designed to involve large numbers or all autonomies in the intergovernmental relations process, thus discouraging bilateral relations. However, in the Organic Law 2/2007, following the example of Catalonia (Organic Law 6/2006), Andalucia shows a clear preference to the Bilateral Commission, recently created, as a vehicle for promoting its competences, a question which will be analyzed in this article, together the competences of cooperation for development (Chapter V), of foreign action (Chapter IV) and of relationships with the European Union (Chapter III). 


\section{Resumen}

El sistema territorial de 1978 (Título VIII) está basado en un principio constitucional, según el cual es potestad de los diferentes territorios iniciar y continuar el proceso autonómico e incluir en sus estatutos, a través de sucesivas reformas, sus respectivas materias y niveles de competencias. Sin embargo, mientras las relaciones intergubernamentales experimentan constantes cambios en el sistema federal comparado desde hace medio siglo, en España, la teoría constitucional no ha progresado en esta materia. Aunque la Constitución Española no establece formalmente una federación, sin embargo, el Estado de las Autonomías ha experimentado un gradual acercamiento al Estado Federal. En España, el discurso federal no es esencial en el debate sobre los poderes de los distintos gobiernos, como es el caso del bilateralismo fiscal o en las negociaciones entre las Comunidades Históricas y el Estado, y, sin embargo, el entendimiento del impacto de las relaciones intergubernamentales entre el Estado, los poderes autonómicos y los niveles locales es muy importante.

En este contexto, después del referéndum de 18 de febrero de 2007, convocado por Decreto 2/2007, de 16 de enero, promulgada por el Presidente del Gobierno autonómico, tras su publicación en el Boletín Oficial del Estado y en el Boletín Oficial de la Junta de Andalucía, el nuevo Estatuto de Autonomía de Andalucía (Ley Orgánica 2/2007, de 19 de marzo) ha entrado en vigor, incluyendo una nueva materia: Ias relaciones intergubernamentales (Título IX. Relaciones institucionales).

Esta Ley Orgánica y otras leyes promueven el establecimiento de instrumentos de colaboración en los sectores con relaciones con el Estado, con otras Comunidades Autónomas, con los niveles locales y con las Comunidades Europeas, en los cuales las competencias de estas Administraciones Públicas pueden converger. Literalmente son cientos de convenios los que gestionan conjuntamente los funcionarios centrales, autonómicos y, a veces, locales. Otras relaciones se articulan a través de conferencias sectoriales, a las que concurren ministros del Gobierno central y consejeros autonómicos, para discutir las materias de su competencia, por ejemplo, medio ambiente, obras públicas, turismo, cultura, educación... Asimismo, una Conferencia de Presidentes reúne al Presidente del Gobierno y a los Presidentes de las Comunidades Autónomas.

Todas estas técnicas están llamadas a involucrar a un gran número de Comunidades Autónomas o a todas ellas en el proceso de relaciones intergubernamentales, desincentivando por tanto las relaciones bilaterales. 
Sin embargo, en la Ley Orgánica 2/2007, siguiendo el ejemplo de Cataluña, Andalucía manifiesta su preferencia por la Comisión Bilateral, recientemente creada, como instrumento para la defensa de sus competencias, cuestión que será analizada en este artículo, junto a las competencias de cooperación al desarrollo (Capítulo V), de acción exterior (Capítulo IV) y de relación con la Unión Europea (Capítulo III). 